\title{
Precipitation Sensitivity to Surface Heat Fluxes over North America in Reanalysis and Model Data
}

\author{
AlEXIS BERG \\ Rutgers, The State University of New Jersey, New Brunswick, and Geophysical Fluid Dynamics Laboratory, \\ Princeton, New Jersey \\ KIRSTEN FINDELL \\ Geophysical Fluid Dynamics Laboratory, Princeton, New Jersey \\ BENJAMIN R. LINTNER \\ Rutgers, The State University of New Jersey, New Brunswick, New Jersey \\ PierRe GENTINE \\ Columbia University, New York, New York \\ CHRISTOPHER KERR \\ University Corporation for Atmospheric Research/GFDL, Princeton, New Jersey
}

(Manuscript received 24 July 2012, in final form 2 January 2013)

\begin{abstract}
A new methodology for assessing the impact of surface heat fluxes on precipitation is applied to data from the North American Regional Reanalysis (NARR) and to output from the Geophysical Fluid Dynamics Laboratory's Atmospheric Model 2.1 (AM2.1). The method assesses the sensitivity of afternoon convective rainfall frequency and intensity to the late-morning partitioning of latent and sensible heating, quantified in terms of evaporative fraction (EF). Over North America, both NARR and AM2.1 indicate sensitivity of convective rainfall triggering to $\mathrm{EF}$ but no appreciable influence of $\mathrm{EF}$ on convective rainfall amounts. Functional relationships between the triggering feedback strength (TFS) metric and mean EF demonstrate the occurrence of stronger coupling for mean EF in the range of 0.6 to 0.8 . To leading order, AM2.1 exhibits spatial distributions and seasonality of the EF impact on triggering resembling those seen in NARR: rainfall probability increases with higher EF over the eastern United States and Mexico and peaks in Northern Hemisphere summer. Over those regions, the impact of EF variability on afternoon rainfall triggering in summer can explain up to $50 \%$ of seasonal rainfall variability. However, the AM2.1 metrics also exhibit some features not present in NARR, for example, strong coupling extending northwestward from the central Great Plains into Canada. Sources of disagreement may include model hydroclimatic biases that affect the mean patterns and variability of surface flux partitioning, with EF variability typically much lower in NARR. Finally, the authors also discuss the consistency of their results with other assessments of land-precipitation coupling obtained from different methodologies.
\end{abstract}

\section{Introduction}

Land-atmosphere interactions are recognized as a major component of the physical climate system. The

Corresponding author address: Alexis Berg, Department of Environmental Sciences, Rutgers, The State University of New Jersey, 14 College Farm Rd., New Brunswick, NJ 08901-8551.

E-mail: alexis.berg@noaa.gov land surface radiative and physical properties, such as albedo, roughness, and water availability, are impacted by atmospheric conditions across a wide range of spatial and temporal scales. In turn, the land surface controls the radiative, moisture, heat, and momentum fluxes between the surface and the atmosphere. Consequently, land surface conditions may feed back on the state of the atmosphere (e.g., Pielke 2001). 
Much research effort has been devoted in recent years to understanding the nature, amplitude, and distribution of the two-way interactions of the land and atmosphere. Land-atmosphere coupling can play a critical role in high-impact phenomena such as floods and droughts (Entekhabi and Brubaker 1995; Paegle et al. 1996; Pal and Eltahir 2003; Fischer et al. 2007; Vautard et al. 2007). From an operational meteorological perspective, knowledge of the impact of surface conditions on the atmosphere may potentially enhance the skill of shortterm and seasonal forecasts in numerical weather prediction models by exploiting the memory inherent in the land surface (Koster and Suarez 2003; Douville 2004; Dirmeyer 2005; Sutton et al. 2006; Conil et al. 2009; Weisheimer et al. 2011; Koster et al. 2011; Seneviratne and Koster 2012). On longer time scales, accurate representation of land-atmosphere interactions is essential for quantifying how climate is impacted by anthropogenic changes to the state of the land surface, for example, land-use-induced land-cover change through deforestation and conversion of natural lands to croplands (Zeng and Neelin 1999; Davin et al. 2007; Findell et al. 2007; Pitman et al. 2009; Pongratz et al. 2010; Teuling et al. 2010; Lee et al. 2011).

One of the key features of land-atmosphere interactions is the soil moisture-precipitation feedback: how soil moisture may enhance or dampen subsequent precipitation over a given region through its impacts on the partitioning of the surface water and energy fluxes [for a comprehensive review, see Seneviratne et al. (2010)]. This potential feedback reflects the coupling between soil moisture and evapotranspiration on the one hand and between evapotranspiration and precipitation on the other hand. While this feedback was initially investigated in the context of moisture recycling, that is, the fraction of precipitation originating from regional evaporation (Rodriguez-Iturbe et al. 1991a,b; Brubaker et al. 1993; Eltahir and Bras 1996), more recent studies have emphasized the role of local interactions, that is, the impact of soil moisture anomalies on boundary layer dynamics and precipitation formation, rather than the absolute moisture changes resulting from modified evaporation (Seneviratne et al. 2010; Gentine et al. 2010, 2011b). Although modeling studies generally report a positive relationship between soil moisture, evapotranspiration, and precipitation, climate models show little consistency in the magnitude of the feedback (Koster et al. 2004; Guo et al. 2006), with some models exhibiting little or no coupling (Lawrence and Slingo 2005) or a negative feedback in some regions (Cook et al. 2006). Indeed, some studies performed with single-column or cloud-resolving models suggest that, under specific conditions, convection may be facilitated over dry soils, in effect producing a negative feedback (Findell and Eltahir 2003a,b; Hohenegger et al. 2009).

Direct empirical feedback analyses have thus far been unable to shed much light on the issue, mostly because of the paucity of long-term, extensive measurements of soil moisture, surface fluxes, and boundary layer state. Using various combinations of observations, reanalysis data, and model outputs, several studies (Zhang et al. 2008; Dirmeyer et al. 2009b; Zeng et al. 2010) have attempted to characterize the soil moisture-precipitation feedback with statistical tools such as lagged correlations and covariance; however, because of various issues pertaining to the compounding effects of soil moisture memory, rainfall variability, and persistence, including the effect of precipitation on soil moisture, such studies should be interpreted with caution (Wei et al. 2008; Orlowsky and Seneviratne 2010). Overall, fairly large uncertainties remain regarding the sign and amplitude of the soil moisture-rainfall feedback in observations.

In the present study, we employ a methodology recently introduced in Findell et al. (2011) that characterizes the strength of the atmospheric branch of the soil moisture-precipitation feedback, that is, the connection between surface fluxes and precipitation. The connection between surface evapotranspiration and subsequent precipitation is recognized as a critical but still uncertain link in the soil moisture-precipitation feedback loop (Seneviratne et al. 2010). Findell et al. investigated the impact of before-noon surface heat flux partitioning on subsequent afternoon rainfall during the summer season in the United States and Mexico using data from the North American Regional Reanalysis (NARR; Mesinger et al. 2006). Given that NARR assimilates hourly rainfall and screen-level air temperature measurements and that surface turbulent fluxes are strongly constrained by the assimilation of near-surface data (Mahfouf 1991; Bouttier et al. 1993), NARR arguably represents a reasonable approximation of reality and offers an internally consistent framework to assess soil-atmosphere feedbacks.

Findell et al. (2011) determined that high values of summertime evaporative fraction $(\mathrm{EF})$, the ratio of latent heat flux to the sum of latent and sensible heat fluxes, lead to increased likelihood of afternoon rainfall but are not strongly tied to afternoon rainfall intensity or accumulated depth. Here we expand the analysis of Findell et al. (2011) to all seasons in NARR and compare their metrics to those calculated from a simulation of the Geophysical Fluid Dynamics Laboratory's Atmospheric Model 2.1 (AM2.1; GFDL Global Atmospheric Model Development Team 2004; Delworth et al. 2006). The remainder of the paper is organized as follows. After outlining the data, models, and methods in section 2, we compare the seasonal results for NARR 
and AM2.1 (section 3). Then we discuss the agreement on feedback assessment in both datasets and describe some of the potential sources of errors and uncertainty (section 4) before discussing our results with respect to other landprecipitation feedback assessments in section 5.

\section{Data, model, and methodology}

\section{a. The NARR dataset}

NARR (Mesinger et al. 2006) is a reanalysis product covering North America over the 25-yr time period $1979-2003$ at 3 -h intervals and $1 / 3^{\circ}$ resolution $(\sim 30 \mathrm{~km})$. This dataset is derived from a data assimilation scheme with near-surface humidity and wind observations ingested hourly and atmospheric profiles of temperature, winds, and moisture from rawinsondes and dropsondes ingested every $3 \mathrm{~h}$. As noted in Findell et al. (2011), the main strength of this reanalysis product, beyond its high spatiotemporal resolution and improvements of its underlying modeling components, is that hourly precipitation data are ingested, in contrast to other reanalysis products where rainfall is purely a model-diagnosed quantity. It should be noted that precipitation is not assimilated directly; rather, vertical profiles of latent heating are derived from precipitation analyses and then fed into the underlying model convection scheme (Mesinger et al. 2006). As a result, Bukovsky and Karoly (2007) find that NARR provides a much improved representation of precipitation over that of other reanalysis products in terms of spatial distribution and diurnal and annual cycle. Furthermore, Becker et al. (2009) demonstrate that mean seasonal rainfall amounts in NARR closely approximate observations throughout the year, while Ruane (2010) attributes NARR's reasonable representation of diurnal cycles over North America in summer, including the nocturnal rainfall maximum over the Midwest, to precipitation assimilation. Despite these improvements, precipitation in NARR is not strictly equivalent to observations; for example, while most daily mean values are comparable to observations, daily distributions of rainfall in NARR are slightly skewed toward more frequent, lighter events than in observations (Becker et al. 2009).

Apart from the NARR improved rainfall accuracy, we are also interested in exploiting "the space-time consistency of various other precipitation-dependent NARR variables" (Mesinger et al. 2006), most notably surface heat fluxes. That is, to leading order, the NARR dataset is both observationally constrained and internally physically consistent in terms of surface fluxes and precipitation and thus offers a unique test bed for investigations of evaporation-precipitation connections. Although surface fluxes in NARR are ultimately model derived (given the lack of extensive observations), they are constrained by the assimilation of near-surface data (Mahfouf 1991; Bouttier et al. 1993). As in Findell et al. (2011), we restrict our study here to data south of $50^{\circ} \mathrm{N}$ since the quality and quantity of observations in Canada are limited.

The native NARR data are available on a Lambert conformal grid (3-hourly, approximately $32 \mathrm{~km}$ ) in gridded binary (GRIB) format. For the Findell et al. study, the data were interpolated using a bilinear interpolation scheme onto a $1 / 3^{\circ} \times 1 / 3^{\circ}$ latitude-longitude grid in network Common Data Forum (netCDF) format. In the present study, the data were further regridded to a $2.0^{\circ}$ latitude $\times 2.5^{\circ}$ longitude resolution so as to compare directly with the output from the simulation (see below). Since the regridding to a coarser resolution is applied to the variables before computation of the feedback metrics, the latter are not simply averages of the higher resolution metrics.

\section{b. AM2.1 climate model}

AM2.1 is the atmospheric component of the Coupled Model 2.1 (CM2.1; Delworth et al. 2006) used in phase 3 of the Coupled Model Intercomparison Project (CMIP3). AM2.1 uses a finite-volume atmospheric dynamical core (Lin 2004) with a horizontal resolution of $2^{\circ}$ latitude $\times$ $2.5^{\circ}$ longitude and 24 vertical levels. In the vertical AM2.1 uses a hybrid coordinate ranging from approximately $30 \mathrm{~m}$ above the surface up to $3 \mathrm{hPa}$, or $\sim 40 \mathrm{~km}$ above the surface. A full description of AM2.1 and its comparison of with observations are provided in GFDL Global Atmospheric Model Development Team (2004).

The coupled Land Model 2.1 (LM2.1) component is based on the land dynamics model described by Milly and Shmakin (2002), with modifications prompted by coupling to, and tuning with, the atmospheric component. Model parameters potentially affecting land-atmosphere interactions, such as albedo, roughness length, stomatal conductance, rooting depth, and soil heat capacity, vary spatially as functions of mapped vegetation types and soil types but are temporally invariant. At unglaciated land points, water is stored in three lumped reservoirs: snowpack, soil water, and groundwater. Soil water is treated as one reservoir representing plant root zone, with vegetationdependent depths of order $1 \mathrm{~m}$. Evapotranspiration is limited by a non-water-stressed bulk stomatal resistance and a soil-water-stress function. Total soil depth is $6 \mathrm{~m}$, with 18 layers for the purposes of computing soil temperature. In terms of land-atmosphere studies, a similar version of this model was used in phases I and II of the Global LandAtmosphere Coupling Experiment (GLACE) experiment (Koster et al. 2004; Guo et al. 2006; Koster et al. 2011).

The simulation analyzed in this study covers the same time period (1979-2003) as the analysis of Findell et al. 
(2011), with prescribed time-varying sea surface temperatures from the Hadley Centre Sea Ice and Sea Surface Temperature dataset (HadISST; Hurrell et al. 2008), land cover, greenhouse gas concentrations, and a $3 \mathrm{D}$ multispecies aerosol climatology. For the sake of comparison with the NARR dataset and computation of the soil moisture-precipitation feedback metrics (see below), 3-hourly mean model data fields are saved.

\section{c. Derivatives and metrics}

\section{1) FEEDBACK METRICS: TFS AND AFS}

Following Findell et al. (2011), we use two metrics to assess the diurnal influence of surface fluxes partitioning on rainfall: the triggering feedback strength (TFS) reflects how afternoon rainfall frequency changes with morning EF, and the amplification feedback strength (AFS) reflects how accumulated afternoon rainfall varies with $\mathrm{EF}$ when afternoon rainfall occurs. The evaporative fraction (EF) is assumed to remain constant in the morning. The validity of this assumption and its consequences are discussed in detail in Gentine et al. (2007, 2011a). Each metric is computed separately for each spatial gridpoint and for each of the four climatological seasons [March-May (MAM), JuneAugust (JJA), September-November (SON), and December-February (DJF)]. by

Over one gridpoint and one season, the TFS is given

$$
\mathrm{TFS}=\sigma_{\mathrm{EF}} \frac{\overline{\partial \Gamma(r)}}{\partial \mathrm{EF}},
$$

where $\sigma_{\mathrm{EF}}$ is the day-to-day standard deviation of morning (0900-1200 LT) EF, $\Gamma(r)$ the probability of afternoon (1200-1800 LT) rain (afternoon rainfall is considered to occur with afternoon accumulations exceeding $1 \mathrm{~mm}$ ), and the overbar denotes the average of the partial derivative across EF and synoptic conditions so that a single mean representative value is obtained at each location [see section $2 \mathrm{c}(2)$ ]. The derivative term on the rhs of (1) represents the sensitivity of afternoon rainfall to morning $\mathrm{EF}$ variations, while the $\sigma \mathrm{EF}$ scaling factor represents how much morning EF actually varies from day to day. Similarly, AFS is defined as

$$
\mathrm{AFS}=\sigma_{\mathrm{EF}} \frac{\overline{\partial E[r]}}{\partial \mathrm{EF}},
$$

where $E[r]$ is the expected value of afternoon rainfall amount.

The main idea behind the temporal offsetting of EF and the precipitation values is to isolate causality, namely, morning EF forcing of subsequent precipitation. The data are further filtered to remove large-scale influences potentially affecting both EF and precipitation and to constrain the analysis to days when local surface turbulent fluxes are most conducive to subsequent convective development. First, only days without morning rainfall (i.e., less than $1 \mathrm{~mm}$ ) are retained, which should mitigate influences from long-duration (and often stratiform) rainfall events (Alfieri et al. 2008). Second, days with negative early morning convective triggering potential (CTP) are excluded. The CTP is a measure of the atmospheric stability and of the energy available for convection within a layer $100-300 \mathrm{hPa}$ above the land surface, that is, the pressure interval likely to be critical to subsequent development of the daytime boundary layer [for further details, see Findell and Eltahir (2003a)]. Early morning CTP $<0$ conditions have been shown to be typically too stable to support convection (Findell and Eltahir 2003a). Afternoon rainfall occurring on days with negative morning CTP is thus assumed to arise from synoptic-scale systems. As mentioned in Findell et al. (2011), in summer in the NARR dataset these restrictions remove $10 \%-30 \%$ of days in the eastern United States, $5 \%-10 \%$ in the western United States and northern Mexico, and 30\%-50\% in southern Mexico [see supplementary Fig. S2 in Findell et al. (2011)].

By design, TFS/AFS are limited to afternoon convective rainfall, which is reasonable since convective rainfall over much of the study domain occurs in the afternoon (Ruane 2010; see also Fig. 1). Of course, as noted previously, in some regions (i.e., the Midwest) convective rainfall takes place primarily during nighttime (Dai et al. 1999), a feature that NARR captures correctly (Ruane 2010). As a result, both Findell et al. (2011) and the present analysis account for only a subset of all convective rainfall events in this region. We note, however, that the nocturnal peak of convection over the Midwest is to first order driven by large-scale tropospheric forcing, involving diurnal variations in largescale vertical atmospheric motion and in the strength of moisture convergence due to the Great Plains low-level jet (Liang et al. 2004; Ruane 2010). Because such convective events are not anticipated to be strongly influenced by local morning surface fluxes, not accounting for this regional nighttime convecting regime in our analysis should have little impact on the assessment of surface-flux-related rainfall sensitivity. section 5 elaborates on this issue.

In AM2.1, a larger share of days is removed through restrictions on convective days than in NARR: $10 \%-$ $40 \%$ in the eastern United States and up to $75 \%$ over southern Mexico. Most of these days are removed through the constraint of zero morning rainfall, consistent with 


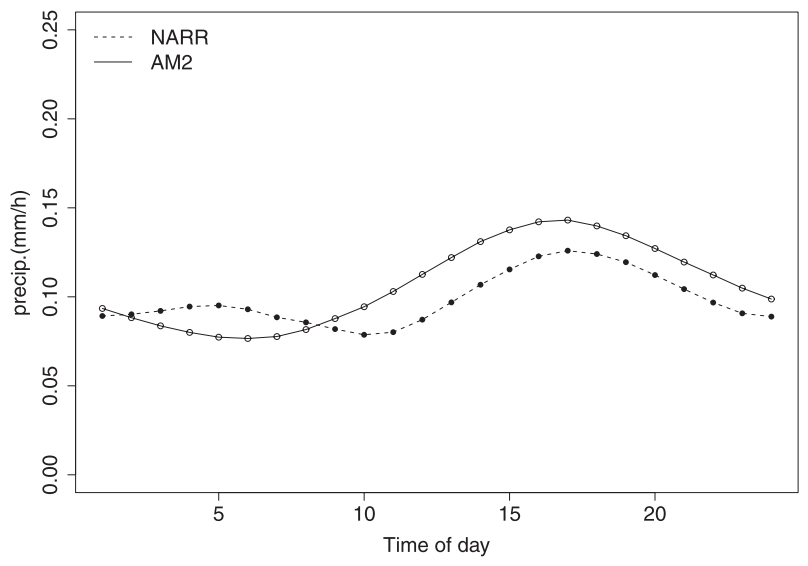

FIG. 1. Mean summertime diurnal cycle of precipitation over land over the study domain (North America between $13^{\circ}$ and $50^{\circ} \mathrm{N}$ ) in AM2.1 and NARR.

the known tendency of GCMs to produce too frequent rainfall [i.e., the drizzle problem discussed in Dai (2006)]. Despite this bias, Fig. 1 shows that the mean summertime diurnal cycle of precipitation over land (over the study domain) is in phase with that of NARR, with rainfall peaking in the afternoon. Slight nighttime differences might reflect the absence of the nighttime convecting maximum over the Midwest in AM2.1. Finally, in both datasets the AFS calculation is further restricted to days with afternoon rain because the triggering feedback strength already accounts for rain-free afternoons.

\section{2) Computation of the DeRivatives}

In both the NARR dataset and AM2.1 outputs, for each grid point and each season, $\sim 2300$ days are available for analysis (i.e., 25 years, between 90 and 92 days for each season). For each day the 3-h data are locally positioned to determine the data points closest to the local time steps (i.e., 0300, 0600, .. , 2100, 0000 LT). Each data point contains accumulated rainfall depths over the 3-h period, or average values over the 3-h period for other variables. Early morning atmospheric conditions are assessed through two quantities used in previous work (Findell and Eltahir 2003a,b): the convective triggering potential (CTP) [see section $2 \mathrm{c}(1)$ ] and the low-level humidity deficit $\left(\mathrm{HI}_{\text {low }}\right)$. $\mathrm{HI}_{\text {low }}$ is defined as the sum of the dewpoint depressions 50 and $150 \mathrm{hPa}$ above the land surface. CTP and $\mathrm{HI}_{\text {low }}$ are determined from the 0600 LT observation, capturing the state of the low-level atmosphere before sunrise (from 0300 to $0600 \mathrm{LT}$ ). The evaporative fraction, defined as the ratio of latent heat flux (evapotranspiration) $\lambda E$ to sensible $(H)$ and latent heat fluxes at the surface [EF $=$ $\lambda E /(H+\lambda E)]$, is calculated from the noontime observation (0900-1200 LT). Afternoon rainfall is defined over the 6-h period following the noontime EF observation; rainfall occurs when the total amount exceeds $1 \mathrm{~mm}$.

We treat $\mathrm{EF}, \mathrm{HI}_{\text {low }}$, and $\mathrm{CTP}$ as discrete random variables, with the parameter space of these variables divided into discrete bins. The CTP and $\mathrm{HI}_{\text {low }}$ thresholds for these bins are predefined so that results can be interpreted in the context of the CTP- $\mathrm{HI}_{\text {low }}$ framework. The EF bins, however, are specific to each grid point: they are determined by splitting the observed range of EF data into 10 bins with an equal number of data points in each bin. For each CTP-HI $\mathrm{H}_{\text {ow }}$ pair, the probability of afternoon rainfall for each EF bin is expressed as

$$
\begin{gathered}
\Gamma(r \mid x, y, \zeta) \triangleq \\
=\Gamma(r \mid x \leq \mathrm{CTP}<x+\Delta x, y \leq \mathrm{HI}<y \\
+\Delta y, \zeta \leq \mathrm{EF}<\zeta+\Delta \zeta) .
\end{gathered}
$$

We use the more concise notation on the lhs of (3) in subsequent equations. We take advantage of properties of conditional probabilities to calculate the dependence of afternoon rainfall on $\mathrm{EF}$, considering all $\mathrm{CTP}-\mathrm{HI}_{\text {low }}$ pairs within each EF bin:

$$
\begin{aligned}
\frac{\overline{\partial \Gamma(r)}}{\partial \mathrm{EF}}= & \frac{\partial}{\partial \mathrm{EF}} \sum_{\zeta=1}^{\zeta_{\max }} \Gamma(r, \zeta) \\
= & \sum_{x=1}^{x_{\max }} \sum_{y=1} \sum_{\max } \sum_{\zeta=1}^{\zeta_{\max }}\left[\Gamma(x, y \mid \zeta) \Gamma(\zeta) \frac{\partial}{\partial \mathrm{EF}} \Gamma(r \mid x, y, \zeta)\right. \\
& +\Gamma(r \mid x, y, \zeta)\left(\Gamma(x, y \mid \zeta) \frac{\partial}{\partial \mathrm{EF}} \Gamma(\zeta)\right. \\
& \left.\left.+\Gamma(\zeta) \frac{\partial}{\partial \mathrm{EF}} \Gamma(x, y \mid \zeta)\right)\right] .
\end{aligned}
$$

The full derivation is included in Findell et al. (2011). To obtain the TFS, this derivative is multiplied by $\sigma_{\mathrm{EF}}$. As mentioned above, the TFS calculation includes only those days with no rainfall between 0600 and 1200 LT and with positive CTP values. Furthermore, we wish to consider how the expected value of rainfall changes with $\mathrm{EF}$, considering all CTP- $\mathrm{HI}_{\text {low }}$ pairs. Using a property of the expected value of a positive function, we can represent the expected value in terms of probabilities:

$$
\begin{aligned}
\frac{\overline{\partial E[R]}}{\partial \mathrm{EF}}= & \frac{\partial}{\partial \mathrm{EF}}\left(\int_{r \geq 0}^{\infty} \Gamma(R \geq r) d r\right) \\
= & \sum_{x=1}^{x_{\max }} \sum_{y=1} \sum_{\max } \sum_{\zeta=1}^{\zeta_{\max }}\left[\Gamma(x, y \mid \zeta) \Gamma(\zeta) \frac{\partial}{\partial \mathrm{EF}} E[R \mid x, y, \zeta]\right. \\
& +E[R \mid x, y, \zeta]\left(\Gamma(x, y \mid \zeta) \frac{\partial}{\partial \mathrm{EF}} \Gamma(\zeta)\right. \\
& \left.\left.+\Gamma(\zeta) \frac{\partial}{\partial \mathrm{EF}} \Gamma(x, y \mid \zeta)\right)\right] .
\end{aligned}
$$


This allows us to define the amplification feedback strength in an analogous manner to the TFS, as given by Eq. (2) above. As mentioned previously, the data used in the AFS calculation include only days when afternoon rainfall occurs.

To assess statistical significance, both TFS and AFS computations, for each pixel and each season, are performed over 200 bootstrap samples (with replacement) created from the available $\sim 2300$ days. Note that this is a higher number of bootstrap samples than in Findell et al. (2011), where 50 bootstrap samples were used; the increase in bootstrap samples does not significantly modify the results for NARR, but does give more robust results for AM2.1.

Finally, normalized versions of the TFS and AFS are given by scaling the computed derivatives by the ratio of the relevant mean values:

$$
\text { normTFS }=\frac{\overline{\mathrm{EF}}}{\overline{\Gamma(r)}} \frac{\overline{\partial \Gamma(r)}}{\partial \mathrm{EF}}=\frac{\overline{\mathrm{EF}} / \overline{\Gamma(r)}}{\sigma_{\mathrm{EF}}} \mathrm{TFS} .
$$

Similarly,

$$
\text { normAFS }=\frac{\overline{\mathrm{EF}}}{\overline{E[r]}} \frac{\overline{\partial E[r]}}{\partial \mathrm{EF}}=\frac{\overline{\mathrm{EF} / \overline{E[r]}}}{\sigma_{\mathrm{EF}}} \mathrm{AFS} .
$$

These normalized metrics are unitless and can thus be directly compared to determine the relative importance of triggering versus amplification.

\section{Feedback metrics results}

a. TFS

\section{1) SPATIOTEMPORAL FEEDBACK}

Figure 2 shows the triggering feedback strength for 3-month seasonal means for NARR (left column) and AM2.1 (right column). In terms of the seasonal evolution, broad agreement is seen between NARR and AM2.1: that is, both show almost no signal during Northern Hemisphere (NH) winter (DJF), a weak positive signal emerging in $\mathrm{NH}$ spring (MAM), a maximum in signal extent and strength in NH summer (JJA), and a retreat in $\mathrm{NH}$ autumn (SON). Such behavior is consistent with expectations that land-atmosphere coupling should be stronger in summer (Dirmeyer 2003) because of the coupling between the land surface and the unstable boundary layer. We note that in summer, each month individually contributes nearly equally to the overall TFS signal (not shown): seasonal covariability of rainfall and EF plays little role in our results here. There is also broad agreement in the principal spatial features of the seasonal
TFS, as both NARR and AM2.1 exhibit signals largely concentrated over Central America and the eastern United States. Over these regions, EF variability explains $10 \%-20 \%$ of the observed (day to day) variability in afternoon rainfall probability. However, prominent differences are discernible in two regions: 1) the northern central Great Plains and Rockies, where AM2.1 shows a positive TFS signal in spring and summer while NARR shows little signal, and 2) Mexico, where AM2.1 shows a stronger signal in the south and no signal in the north. Potential sources of these differences are discussed below. Despite these discrepancies, the TFS maps in Fig. 2 indicate comparable impacts of surface fluxes on the probability of afternoon precipitation in NARR and AM2.1.

\section{2) Functional ReLATIONSHiP}

A more functional quantification of the relationship between the TFS and surface fluxes is presented in Fig. 3, which depicts the normalized TFS metric (normTFS) plotted against EF over the study domain. In each of the seasons, the thick lines (corresponding to the mean signal from 200 bootstrap realizations) slope upward with EF, indicating that the EF-related convective triggering impact increases as $\mathrm{EF}$ increases. In both NARR and AM2.1, most of this increase occurs for EF above $\sim 0.6$; over the range $0.2<\mathrm{EF}<0.6$, TFS remains small; beyond 0.6 , it increases substantially.

Across the entire range of mean EF, TFS remains positive. However, for both low and high EF values, both AM2.1 and NARR indicate the possibility of a negative signal; that is, these bins exhibit much larger spread (shaded area indicative of the minimum of the fifth and maximum of the ninety-fifth percentile curves from the bootstrap samples) in normTFS bootstrap values than those with more moderate $\mathrm{EF}$ values, particularly in AM2.1 in which the EF range is greater and the spread among bootstrap members is systematically larger. While the precise nature of the increased spread in AM2.1 is unknown, it may suggest that the impact of surface fluxes on precipitation triggering is less consistent over time in the model since the estimated relationship appears more sensitive to the resampling of days (with replacement).

The possibility of some negative TFS values at low EF values is consistent with the results from Findell et al. (2011), who used the $1 / 3^{\circ} \times 1 / 3^{\circ}$ resolution NARR data. This may point to negative feedback induced by moistening of the top of the boundary layer through entrainment, as observed in a moist midlevel atmosphere (Ek and Holtslag 2004; Westra et al. 2012). This moistening could then favor the formation of deep convective rain. On the other hand, the finer resolution NARR data 


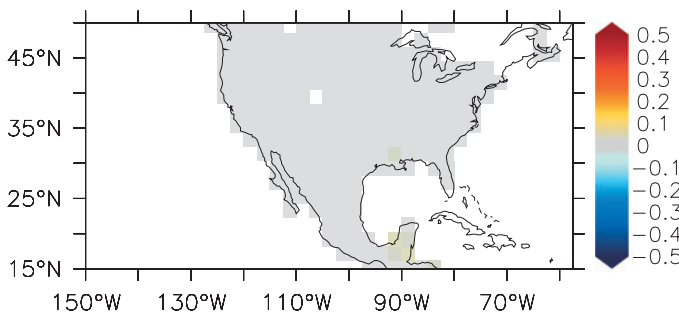

TFS, DJF, NARR

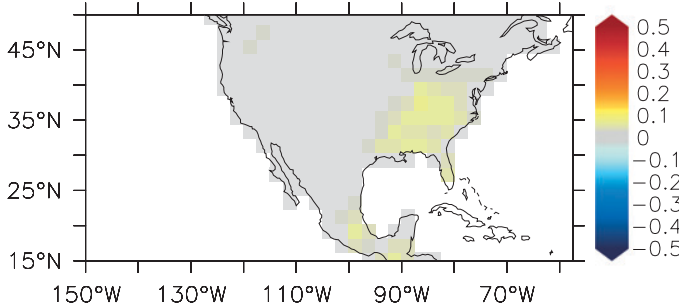

TFS, MAM, NARR

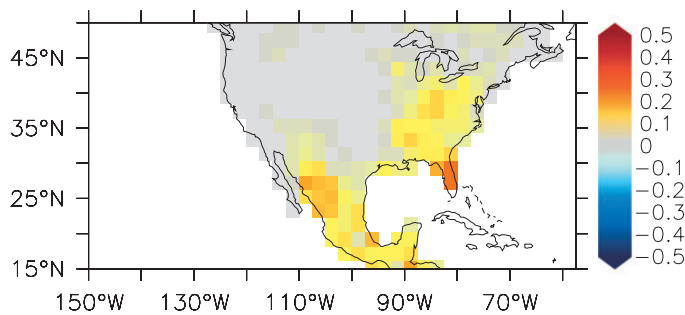

TFS, JJA, NARR

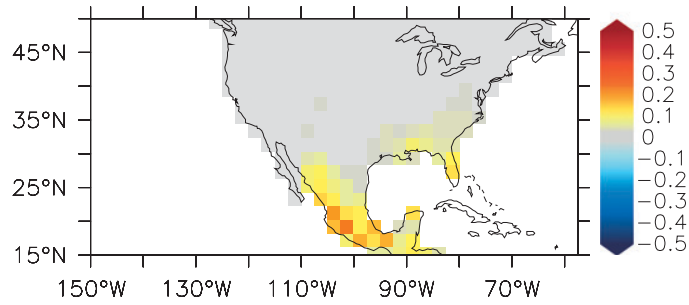

TFS, SON, NARR

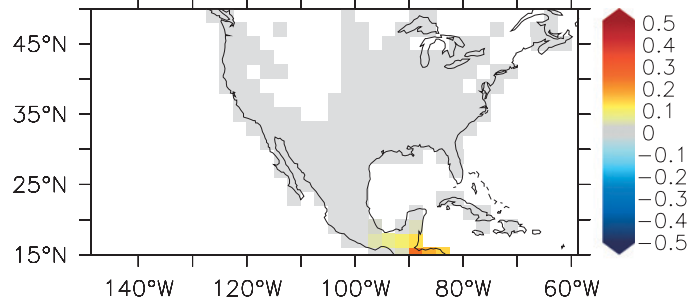

TFS, DJF, AM2.1

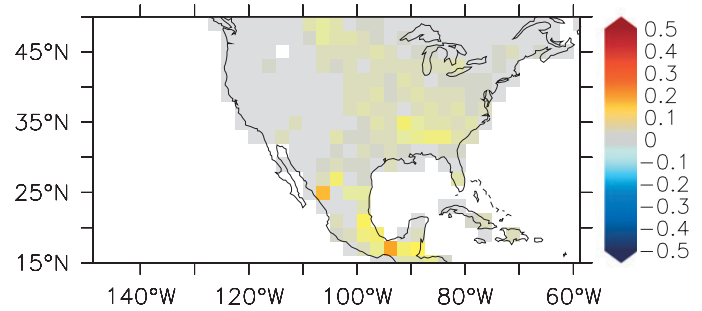

TFS, MAM, AM2.1

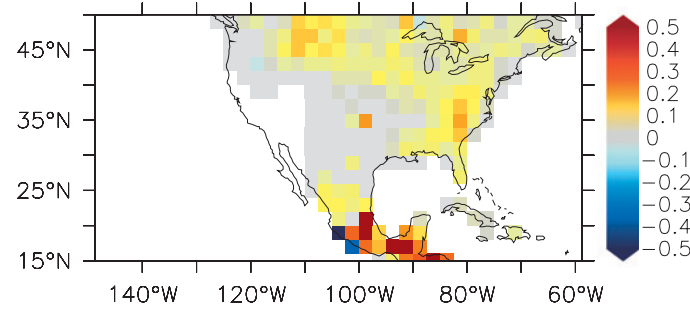

TFS, JJA, AM2.1

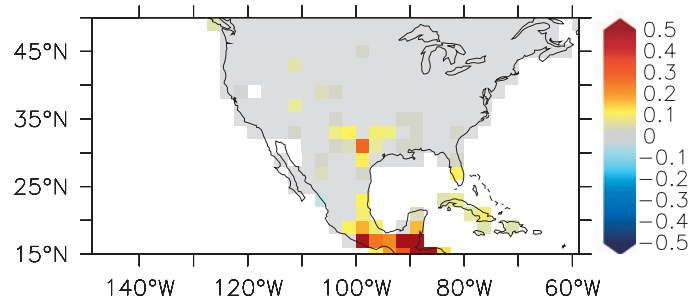

TFS, SON, AM2.1

FIG. 2. Triggering feedback strength TFS [units of probability of afternoon rain (1200-1800 LT)] in (left) NARR and (right) AM2.1 over the different seasons (top to bottom): mean from the 200 bootstrap samples. Gray shading indicates the mean was not significantly different from zero according to a two-sided $t$ test at the $95 \%$ level; white shading indicate points without enough days for the analysis.

show little indication of negative normTFS values at high EF. Thus, the appearance of some negative normTFS values in the regridded NARR indicates that coarsening the resolution may impact the sign of the coupling in some instances.

Finally, the probability distribution functions (pdfs) of mean EF shown in Fig. 3 indicate (thin black lines) that AM2.1generally captures a range of mean EF in the spring and fall seasons similar to NARR, although it is biased toward dry values in the summer season. This bias is further discussed in section $4 \mathrm{~b}$.

\section{b. $A F S$}

The AFS metric in both NARR and AM2.1 (Fig. 4) generally reflects small values and considerable spatial heterogeneity, suggesting a negligible and inconsistent 
NARR
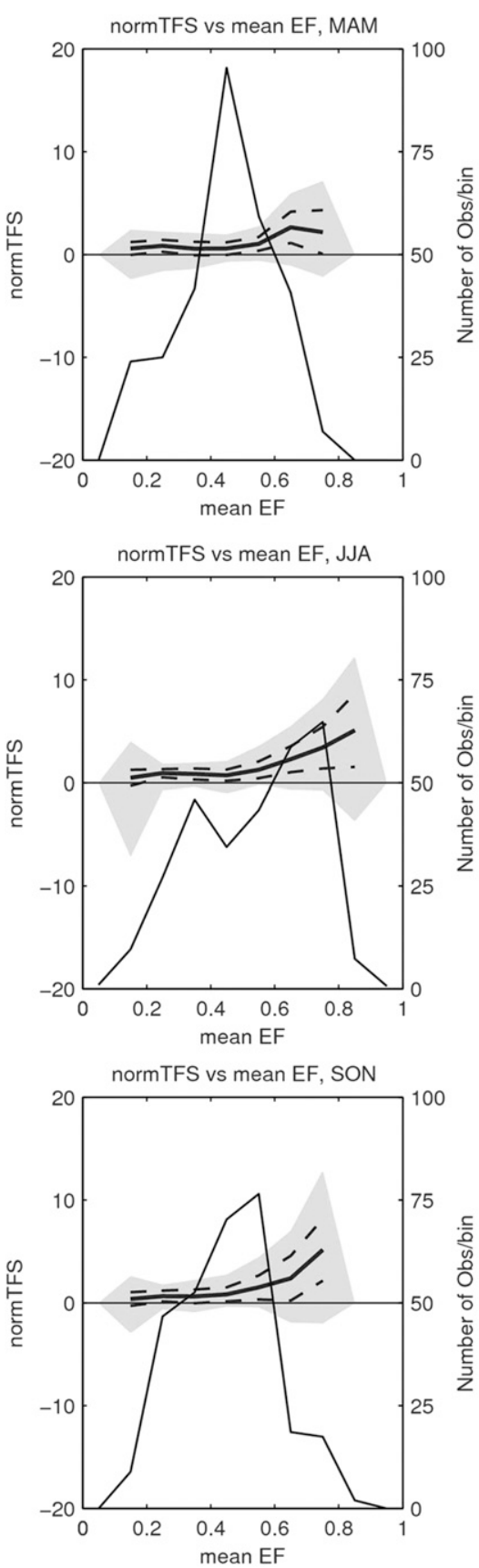

AM2.1
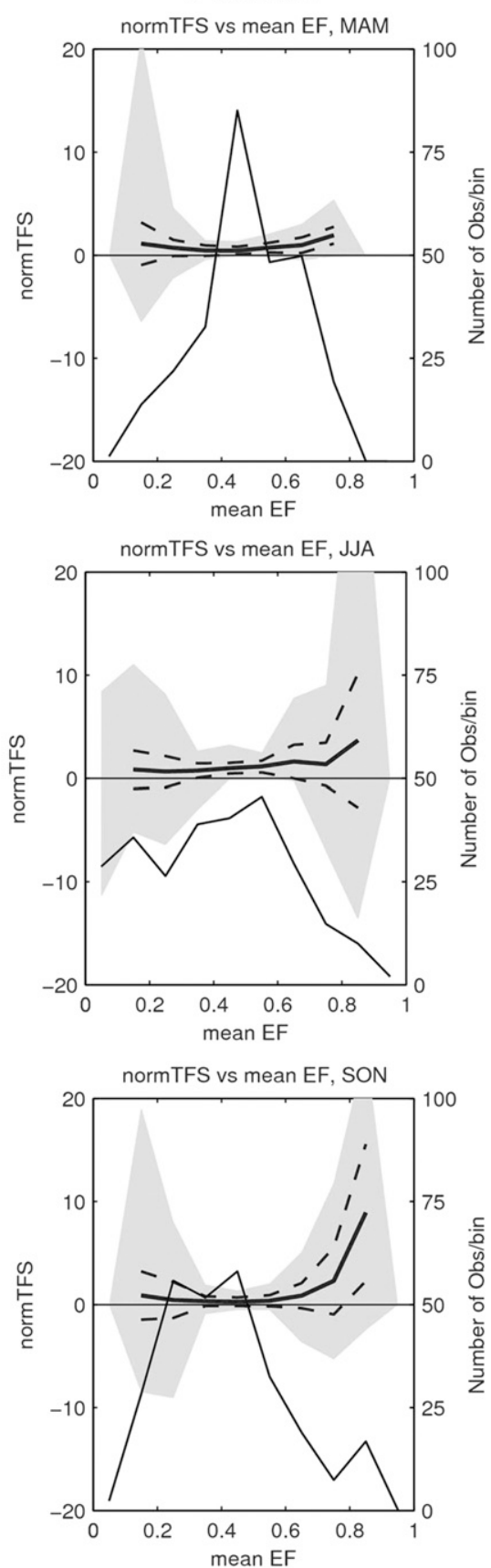

FIG. 3. NormTFS as a function of mean EF (thick line) determined from all grid points (south of $50^{\circ} \mathrm{N}$ ) in each of the 200 bootstrap samples. Shaded areas indicate minimum and maximum values of the fifth and ninety-fifth percentile curves from these bootstrap samples; dashed lines are the mean \pm 1 std dev. The thin black line indicates the mean number of observations per bin (10 bins with an increment of 0.1 ) over the bootstrap samples. Shading is truncated where the mean number of observations per bin is $<5$.

influence of surface fluxes on afternoon rainfall intensity. In fact, the functional plots of normAFS versus mean EF (Fig. 5) for both NARR and AM2.1 hint at weakly positive values for only the highest $\mathrm{EF}$ values
$(>0.8)$ in JJA and SON. These results are consistent with the fine-resolution results of Findell et al. (2011): in the latter, the AFS signal corresponds to $<1 \mathrm{~mm}$ rainfall amplification over high EF regions, which is typically 


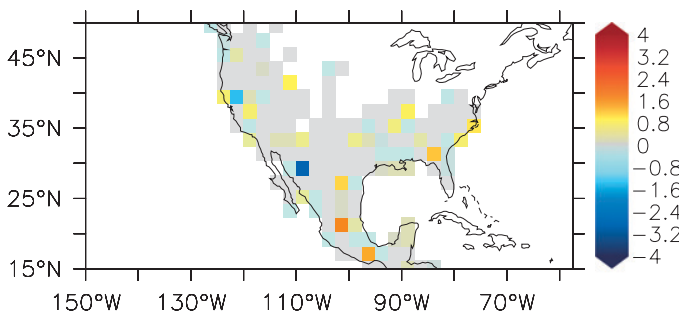

AFS, DJF, NARR

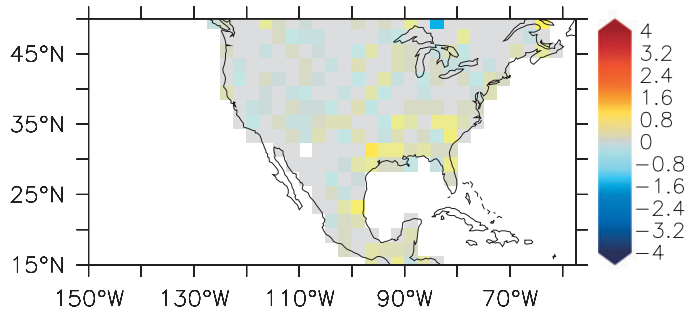

AFS, MAM, NARR

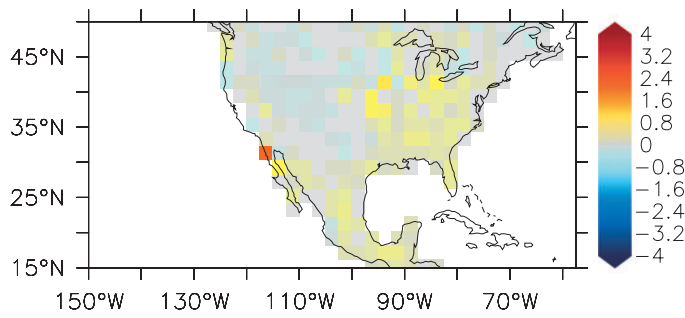

AFS, JJA, NARR

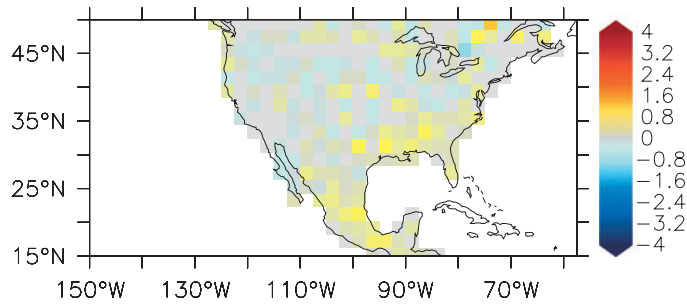

AFS, SON, NARR

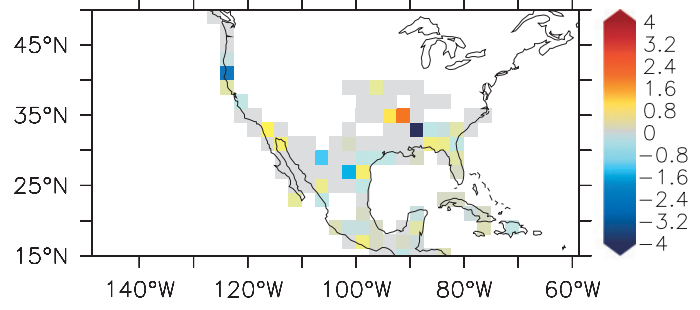

AFS, DJF, AM2.1

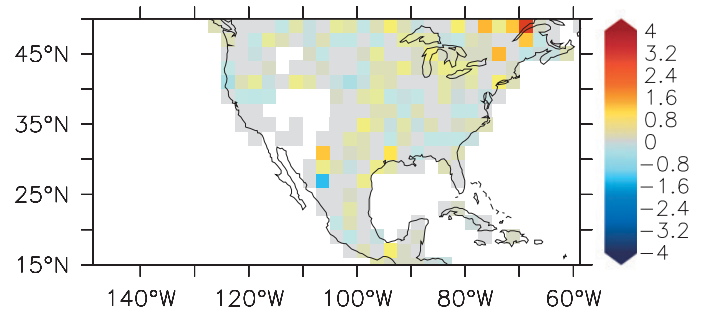

AFS, MAM, AM2.1

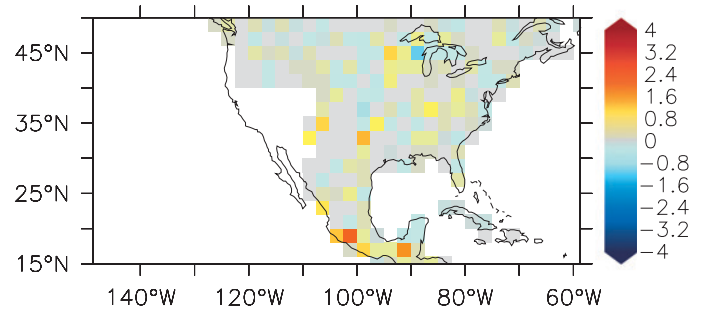

AFS, JJA, AM2.1

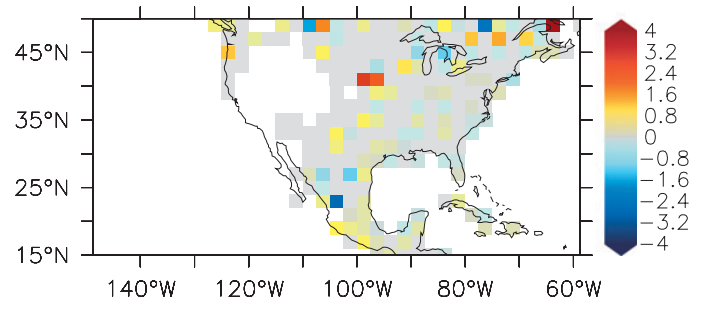

AFS, SON, AM2.1

FIG. 4. As in Fig. 2, but for the amplification feedback strength (AFS) [units of millimeters of afternoon rain (1200-1800 LT)].

less than $10 \%$ of the average afternoon rainfall depths in these regions. As in Fig. 3 for the normTFS, Fig. 5 shows that the spread of normAFS bootstrap values for a given mean EF is much larger in the model than in NARR.

Beyond that leading-order agreement, there are differences between NARR and AM2.1. GCMs exhibit well-known biases in the intensity, variability, and timing of convective rainfall (Betts and Jakob 2002; Dai 2006; Rio et al. 2009), which could contribute to these differences. Relative to NARR, the AM2.1 pdf of morning EF for days with rainy afternoons is skewed toward higher values, with a peak at $\mathrm{EF}=0.7$ in JJA, as seen in Fig. 5. The difference between the distributions of EF on all days versus rainy days (Fig. 3 versus Fig. 5) is greater in AM2.1 than in NARR. This suggests that AM2.1 simulates a larger proportion of days with midrange EF and no afternoon rainfall, with afternoon rainfall preferentially occurring on days with high morning EF. This suggests that the atmosphere, precipitation in particular, may be less sensitive to surface fluxes in AM2.1 than in 

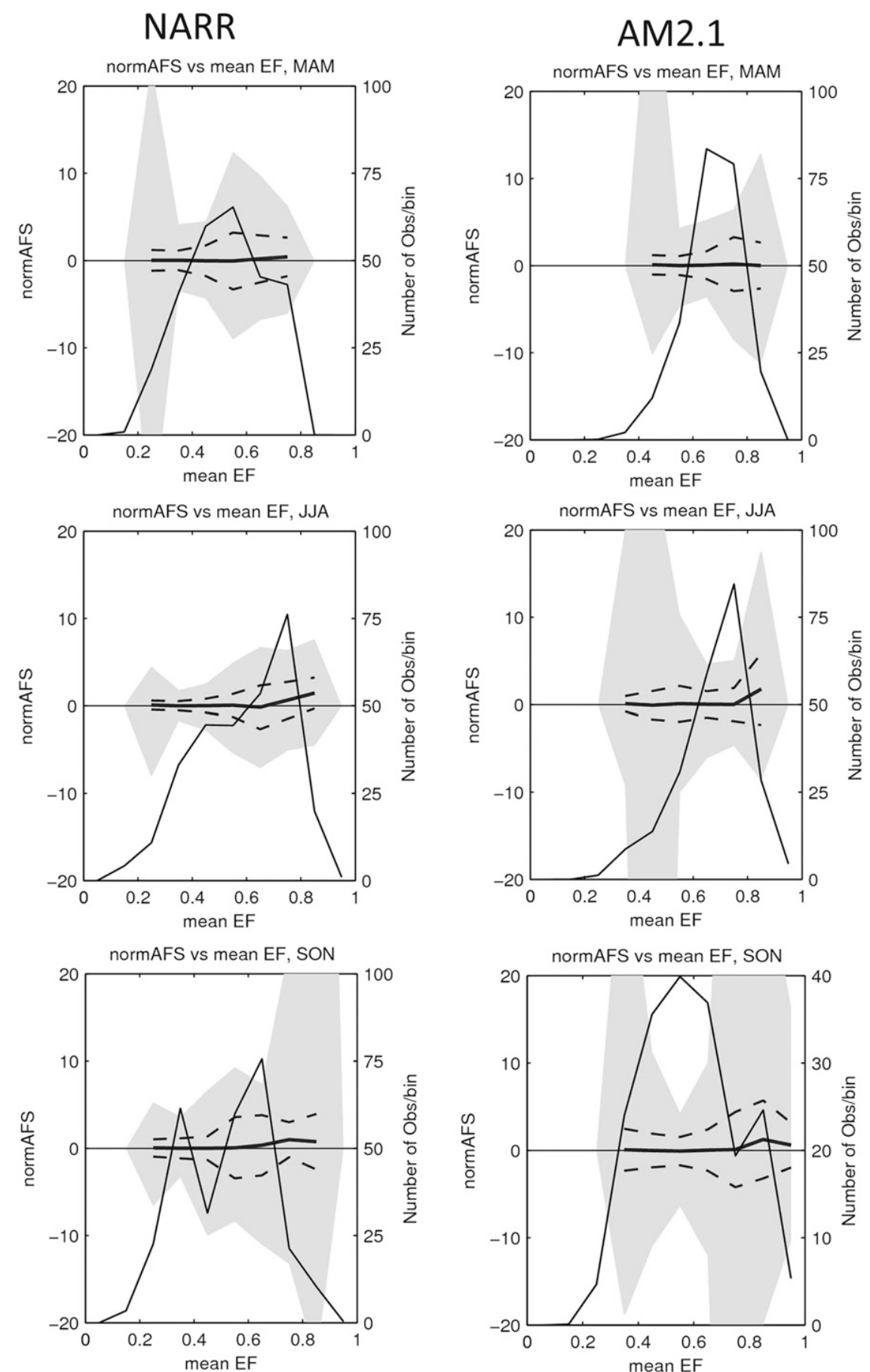

FIG. 5. As in Fig. 3, but with normAFS as a function of mean EF. Note that the pdf of mean number of observations per bin differs from Fig. 3 because only days with afternoon rainfall are included in the AFS calculation.

NARR, as the former seemingly requires a higher EF to trigger rainfall. This is consistent with rainfall sensitivity results discussed in section 4a below.

To summarize, Figs. 2-5 demonstrate that in both NARR and AM2.1 surface flux partitioning may exert substantial control on afternoon rainfall triggering in some regions but little overall control on the amount of rain that falls. The next section investigates in greater detail some of the differences in TFS between NARR and AM2.1; given the negligible 


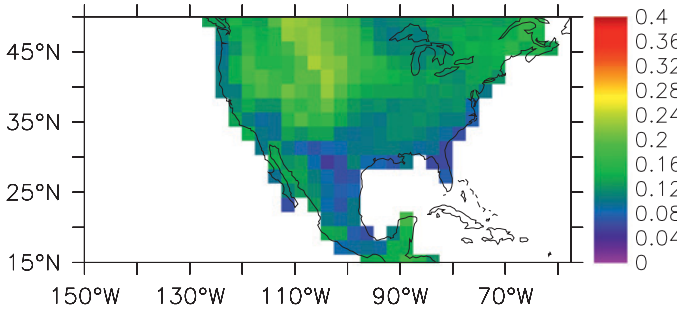

EF std. dev., DJF, NARR

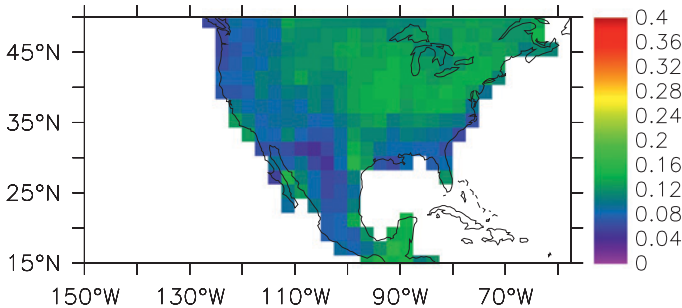

EF std. dev., MAM, NARR

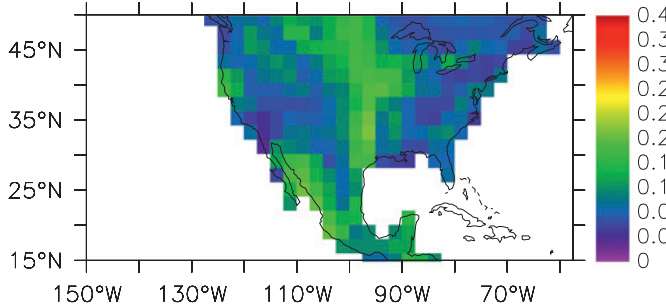

EF std. dev., JJA, NARR

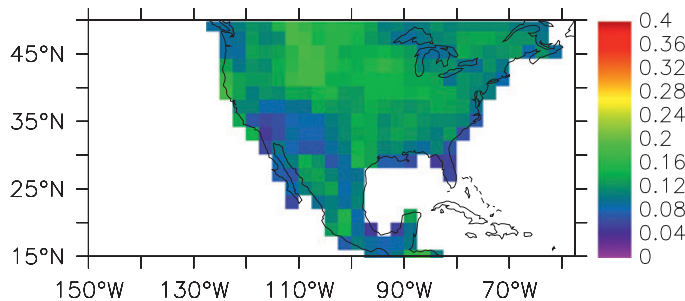

EF std. dev., SON, NARR

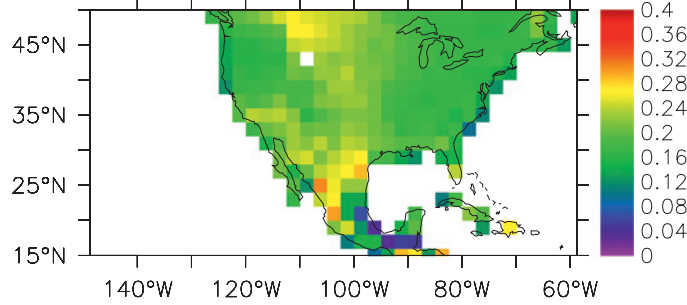

EF std. dev., DJF, AM2.1

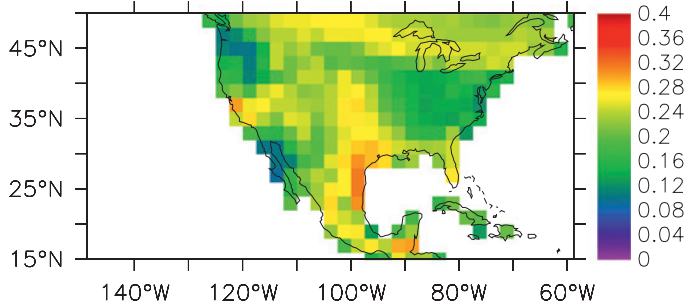

EF std. dev., MAM, AM2.1

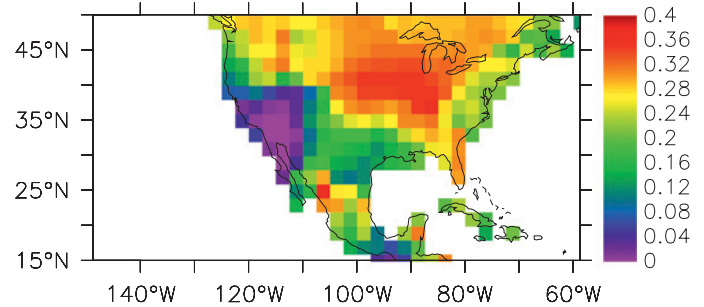

EF std. dev., JJA, AM2.1

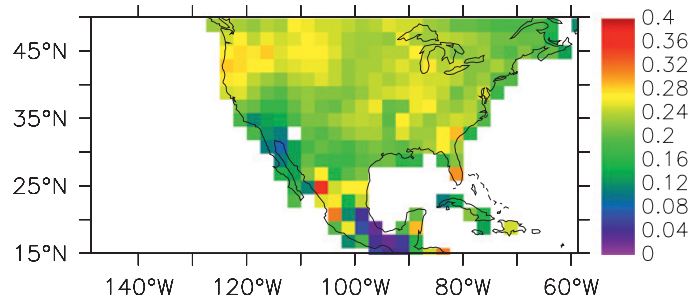

EF std. dev., SON, AM2.1

FIG. 6. Standard deviation of morning (0900-1200 LT) EF in (left) NARR and (right) AM2.1 over the different seasons (top to bottom): mean from the 200 bootstrap samples. Note that for each season days with morning rainfall or negative morning CTP were removed.

AFS signal, differences for that metric are not described.

\section{Feedback drivers in NARR and AM2.1 \\ a. TFS components}

As discussed in section $2 \mathrm{c}$, the TFS computation involves the combination of two terms: a derivative

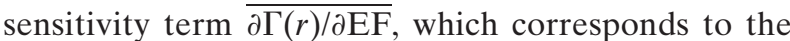
sensitivity of afternoon rainfall probability to morning $\mathrm{EF}$, and a scaling factor $\sigma_{\mathrm{EF}}$, which reflects the day-today variability of EF. Figures 6 and 7 depict these terms seasonally for both NARR and AM2.1. Overall, these terms manifest some significant differences between the two datasets: in general, AM2.1 shows approximately twice the EF variability of NARR (Fig. 6), while the AM2.1 sensitivity term is only half as 


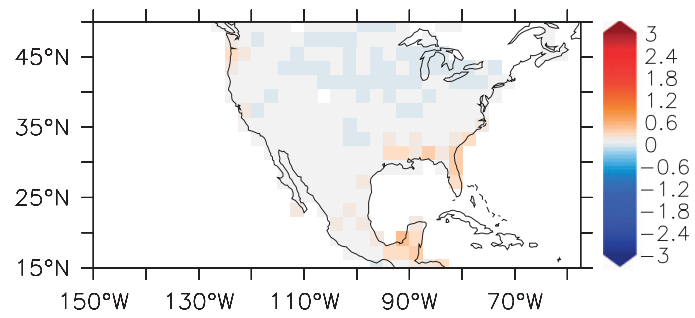

$\mathrm{dP} / \mathrm{dEF}, \mathrm{DJF}, \mathrm{NARR}$

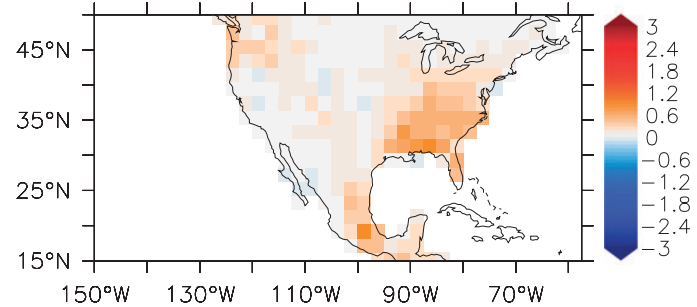

$\mathrm{dP} / \mathrm{dEF}, \mathrm{MAM}, \mathrm{NARR}$

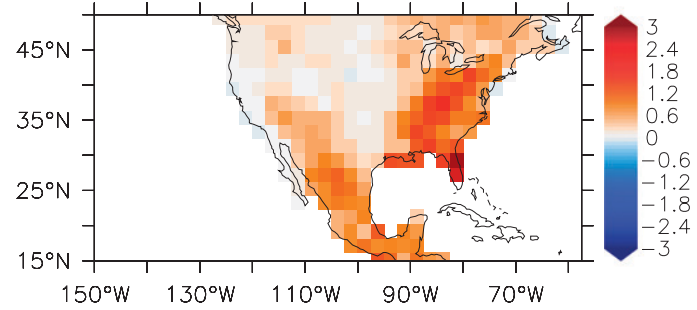

$\mathrm{dP} / \mathrm{dEF}$, JJA, NARR

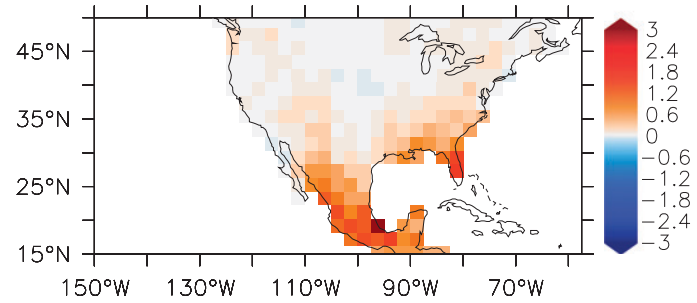

$\mathrm{dP} / \mathrm{dEF}$, SON, NARR

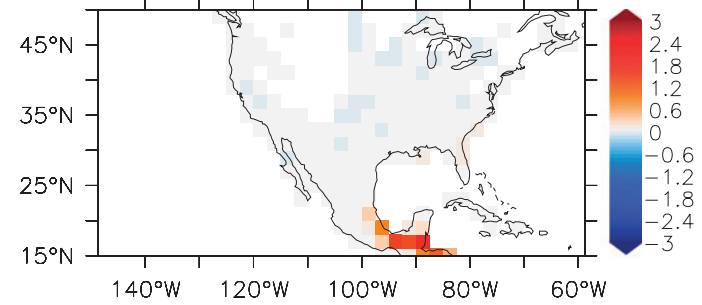

$\mathrm{dP} / \mathrm{dEF}, \mathrm{DJF}, \mathrm{AM} 2.1$

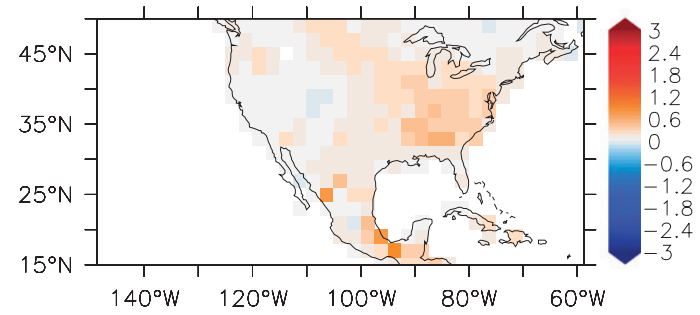

$\mathrm{dP} / \mathrm{dEF}, \mathrm{MAM}, \mathrm{AM} 2.1$

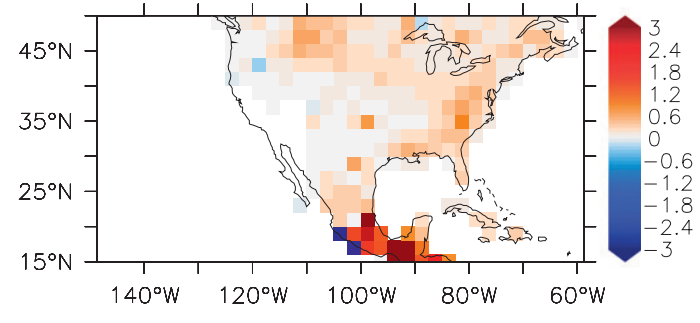

dP/dEF, JJA, AM2.1

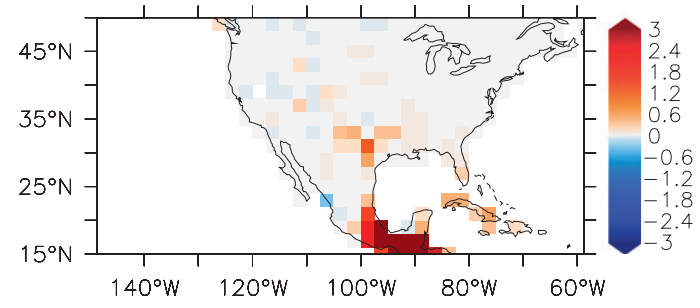

$\mathrm{dP} / \mathrm{dEF}$, SON, AM2.1

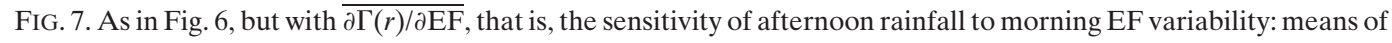
the 200 bootstrap samples.

large (Fig. 7). As a result, the consistency of the TFS signals in NARR and AM2.1 arises by offsetting differences, with AM2.1 exhibiting comparable TFS to NARR through the product of lower sensitivity and higher EF variability.

On the other hand, differences in the TFS patterns in NARR and AM2.1 appear to mirror differences in

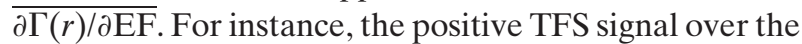
northern Great Plains and Rockies in JJA in AM2.1 stems from a strong simulated sensitivity in AM2.1 over those regions; since $\sigma_{\mathrm{EF}}$ is also much larger there, a rather strong TFS signal occurs in AM2.1 in this region. In contrast, because of low rainfall sensitivity, NARR displays almost zero signal there. Similarly, the differences in TFS patterns over the southwestern United States and Mexico, namely, a stronger signal in AM2.1 compared to NARR in the southern part of this region and an absence of signal in the northern part, primarily

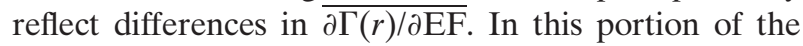
domain, the sensitivity differences are not compensated 


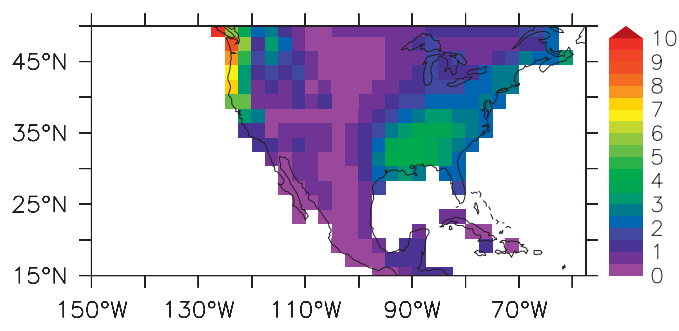

Mean daily rainfall, DJF, NARR

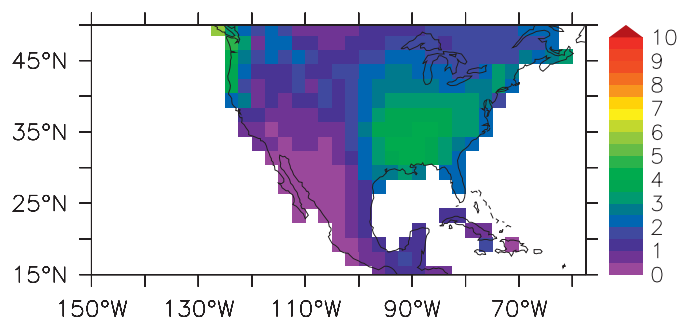

Mean daily rainfall, MAM, NARR

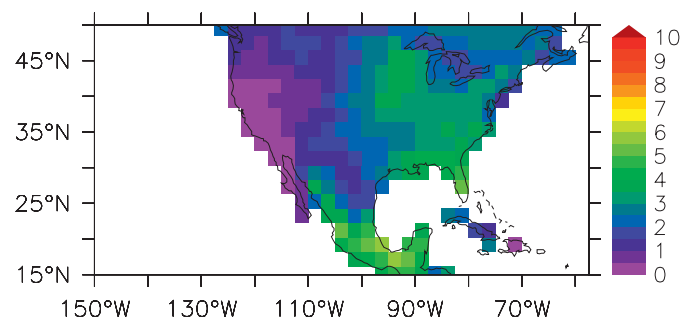

Mean daily rainfall, JJA, NARR

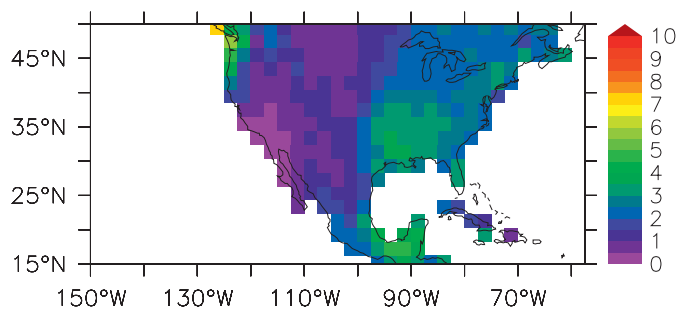

Mean daily rainfall, SON, NARR

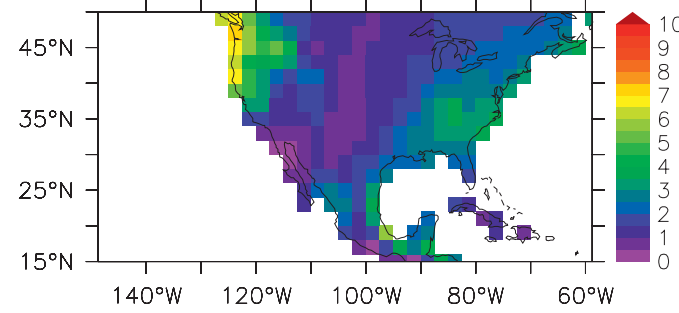

Mean daily rainfall, DJF, AM2.1

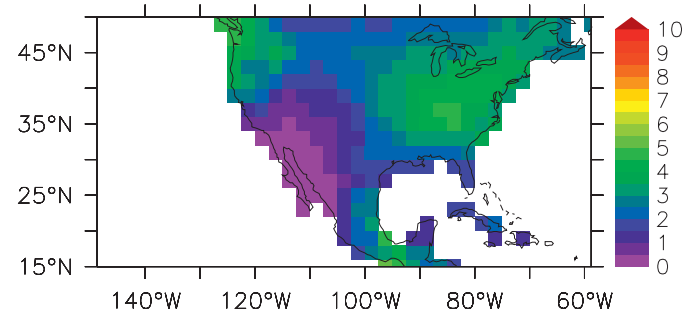

Mean daily rainfall, MAM, AM2.1

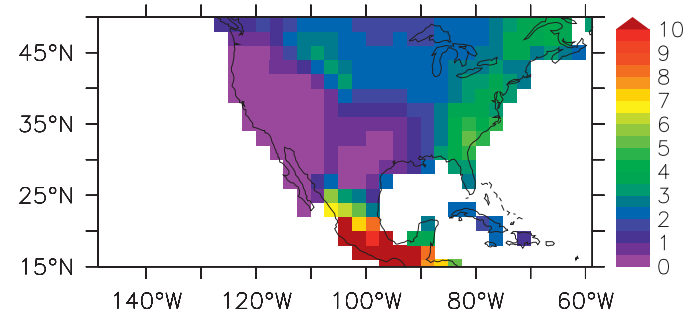

Mean daily rainfall, JJA, AM2.1

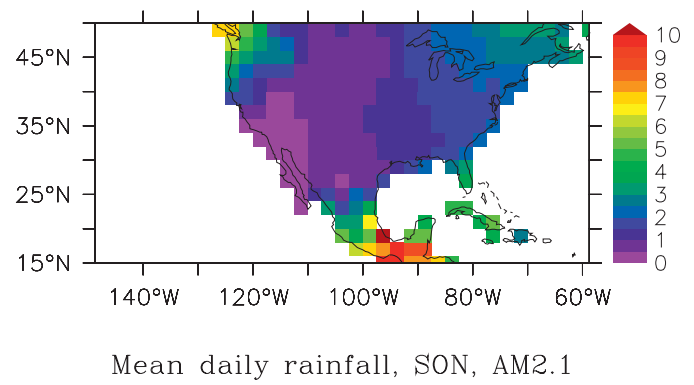

FIG. 8. As in Fig. 6, but with mean daily rainfall $\left(\mathrm{mm} \mathrm{day}^{-1}\right)$. Note that here all days in the season are included.

by differences in $\sigma_{\mathrm{EF}}$. It is also worth pointing out that the region of highest $\sigma_{\mathrm{EF}}$ in JJA in NARR coincides with the location of the central Great Plains hotspot of land-atmosphere coupling of Koster et al. (2004), but this is not the case in AM2.1. That is, the region of largest EF variance in NARR is narrowly confined to the transitional region between the arid west and humid east, while the maximum EF variance in AM2.1 occurs over a much broader region to the northeast.

\section{b. Differences in climate background}

We now consider differences in $\sigma_{\mathrm{EF}}$ and $\overline{\partial \Gamma(r) / \partial \mathrm{EF}}$ in the context of the differing climatological features in the two datasets.

\section{1) RAINFALL}

Figure 8 depicts mean daily rainfall across all seasons in NARR and AM2.1. Broadly AM2.1 replicates the pattern of mean rainfall seen in NARR, particularly in 


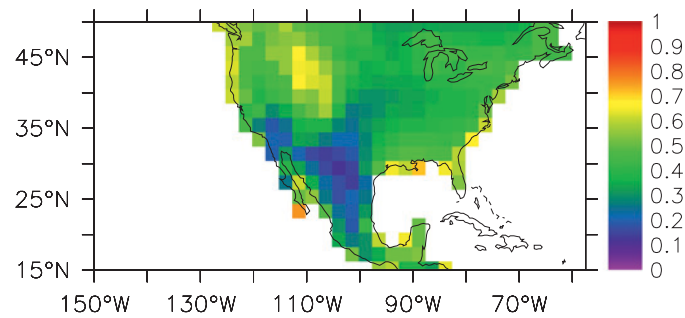

Mean EF, DJF, NARR

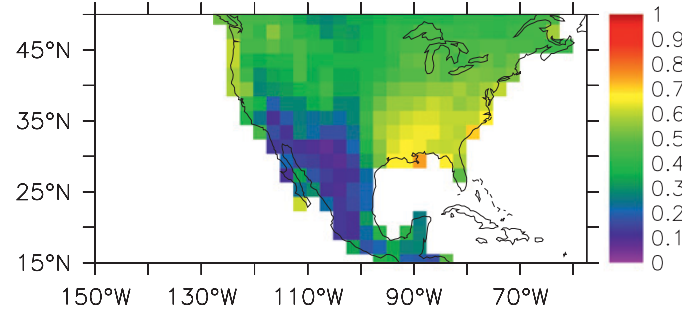

Mean EF, MAM, NARR

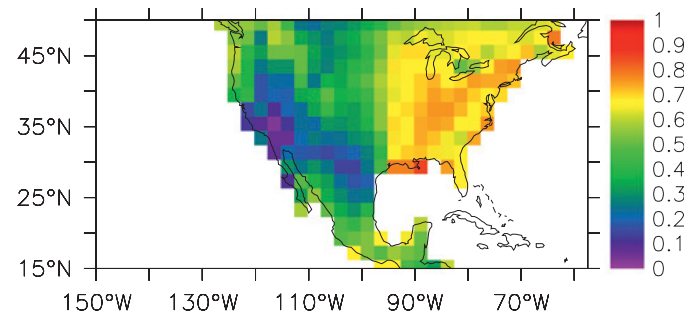

Mean EF, JJA, NARR

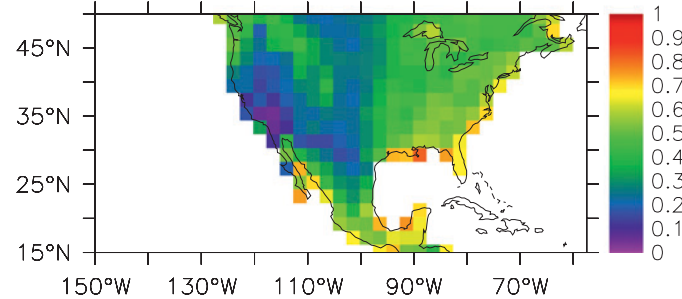

Mean EF, SON, NARR

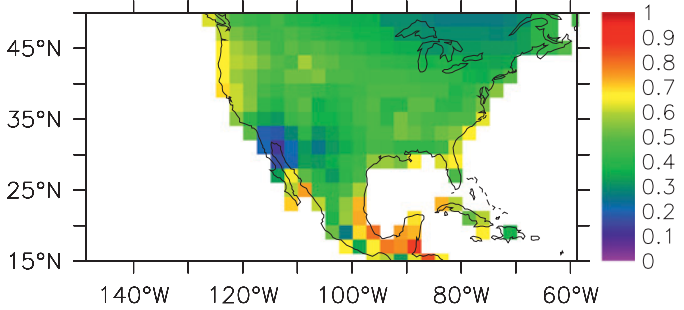

Mean EF, DJF, AM2.1

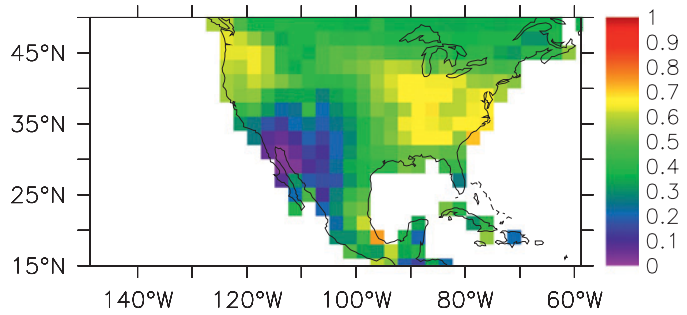

Mean EF, MAM, AM2.1

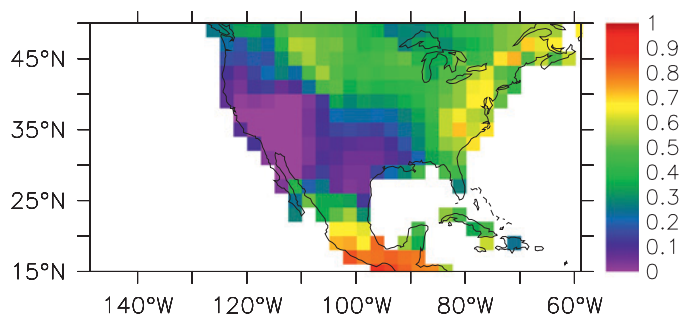

Mean EF, JJA, AM2.1

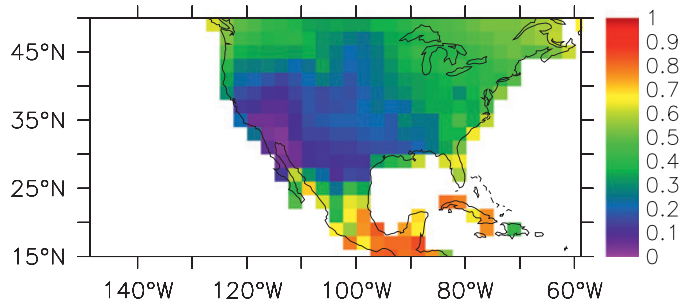

Mean EF, SON, AM2.1

FIG. 9. As in Fig. 6, but with mean morning (0900-1200 LT) EF.

DJF and MAM, although some significant regional biases are present. Most obvious here is the negative bias over the Midwest and south-central United States in JJA (Klein et al. 2006). In JJA the model also appears to overestimate rainfall over the northern Great Plains and Rockies, while in SON, it underestimates rainfall over the eastern United States. Throughout Mexico and Central America over most of the year, AM2.1 largely overestimates rainfall. Comparing mean rainfall and EF patterns (Fig. 9) underscores a strong association between them, with the differences in EF between the two datasets resembling those for rainfall.

Because biases in rainfall translate directly into differences in mean evaporative fraction (Figs. 8 and 9) and because of the relationship between mean EF and the TFS [highlighted in section 3a(2)], biases in rainfall have the potential to directly affect simulated triggering feedback strength. For instance, over areas like Central America, the positive bias in rainfall does not substantially alter afternoon rainfall probability (see Fig. 10) but it does translate into higher mean EF values (Fig. 9). 


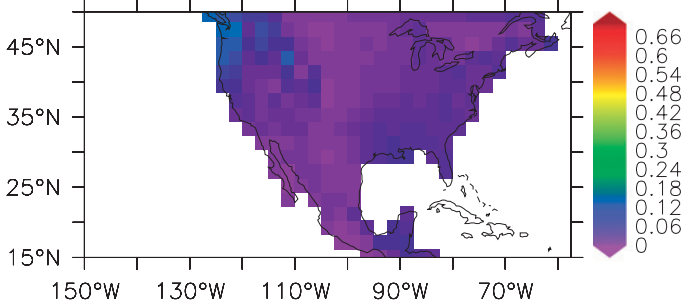

Mean Rain Prob., DJF, NARR

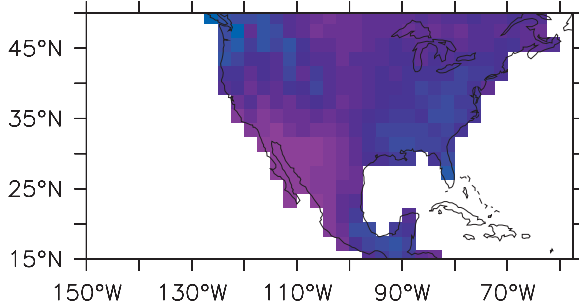

Mean Rain Prob., MAM, NARR

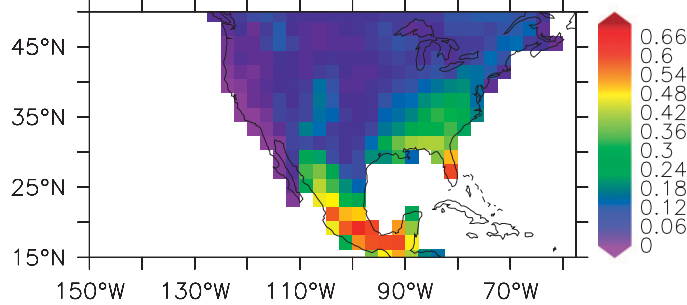

Mean Rain Prob., JJA, NARR

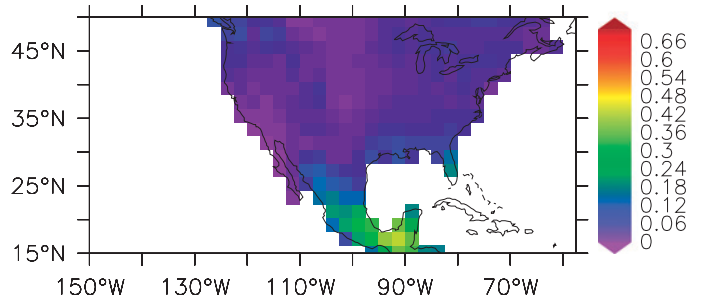

Mean Rain Prob., SON, NARR

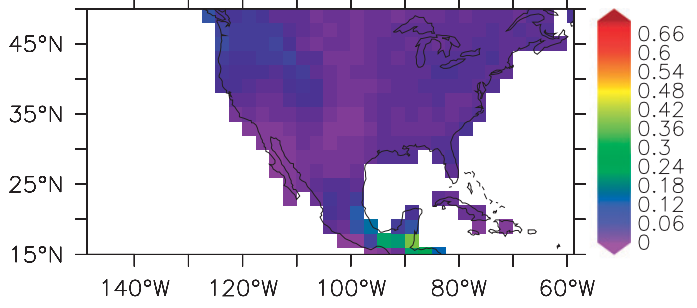

Mean Rain Prob., DJF, AM2.1

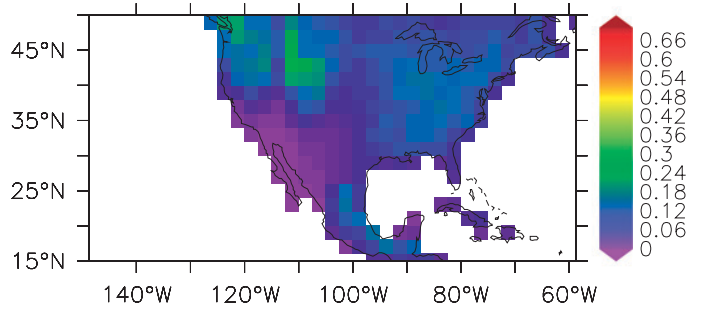

Mean Rain Prob., MAM, AM2.1

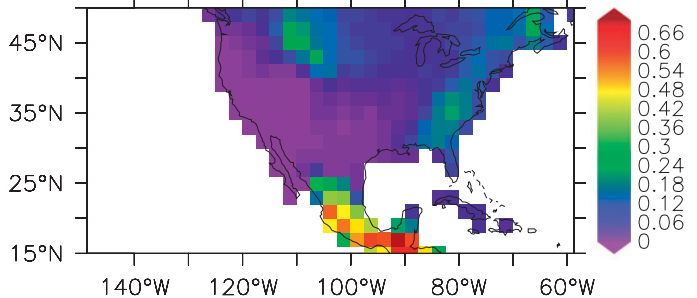

Mean Rain Prob., JJA, AM2.1

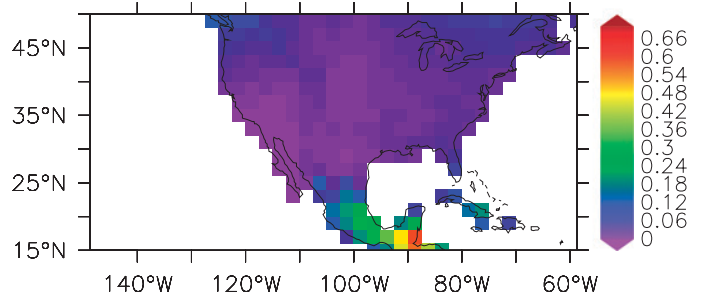

Mean Rain Prob., SON, AM2.1

FIG. 10. As in Fig. 6, but with mean afternoon (1200-1800 LT) rainfall probability.

Given the relationship between mean EF and TFS, this leads to higher sensitivity values (Fig. 7) and, thus, higher TFS (Fig. 2). On the other hand, in regions like the southern and southwestern United States, the dry bias in AM2.1 means that afternoon rainfall probability (Fig. 10) is too low for the sensitivity term, and thus the TFS, to be significant (see section 2).

\section{2) EF VARIABILITY}

As previously discussed, $\sigma_{\mathrm{EF}}$ is more muted in NARR relative to AM2.1. Unfortunately, no gridded, large-scale observational data exist to demonstrate whether $\sigma_{\mathrm{EF}}$ is closer to reality in either NARR or AM2.1. Despite differences in patterns that mostly reflect differences in rainfall, mean EF reaches similar maximum values in both datasets (Fig. 9). As shown in Fig. 11a, because EF is bounded by 0 and 1 during daytime, one expects the relationship between the mean and standard deviation to exhibit a convex shape, with middle-range mean values showing the largest variability. Although the standard deviation versus mean EF curves for both NARR and AM2.1 exhibit the expected shape 

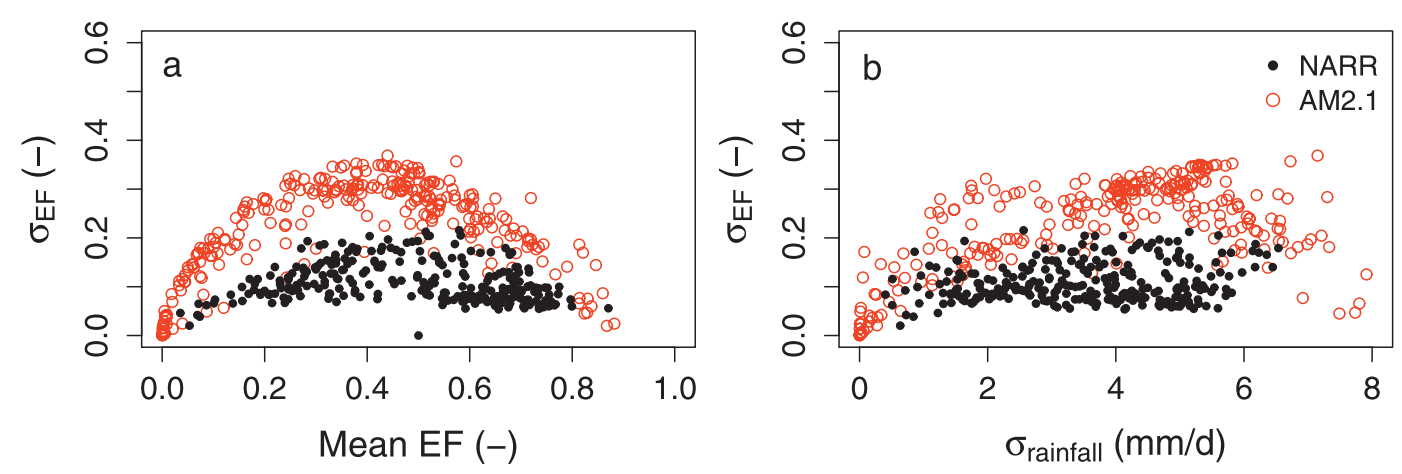

FIG. 11. (a) Standard deviation of morning EF as a function of mean EF; (b) daily rainfall standard deviation for JJA in NARR and AM2.1. Each dot represents a pixel.

(Fig. 11a), the curve is much flatter in NARR. In addition, Fig. 11b shows that morning EF variability in NARR is largely invariant with respect to daily rainfall variability $\left(\sigma_{\text {rainfall }}\right)$. In contrast, in $\mathrm{AM} 2.1, \mathrm{EF}$ variability increases with rainfall variability at low $\sigma_{\text {rainfall }}$, saturates, and then decreases. The decrease of $\sigma_{\mathrm{EF}}$ at higher rainfall variability (which in turn is associated with high mean rainfall conditions) comes about as EF approaches saturation. It remains unclear what role data assimilation in NARR, in which surface fluxes respond to assimilated rainfall but are also affected by the assimilation of near-surface humidity and wind, plays in the low variability of EF.

If $\mathrm{EF}$ variability is, indeed, attenuated in NARR compared to reality, then the TFS quantitative results reported in Findell et al. (2011) are arguably conservative. Overall, we suggest that the differences in mean rainfall and mean $\mathrm{EF}$, combined with the different mean $\mathrm{EF}-\sigma_{\mathrm{EF}}$ relationships in both datasets, explain the very different patterns in EF variability in Fig. 6. While we are unable to assess the respective levels of realism of EF variability in NARR and AM2.1, we stress that $\sigma_{\mathrm{EF}}$ is itself only a scaling factor in the computation of the TFS. Qualitatively, differences in TFS appear to be driven primarily by sensitivity patterns, namely, the relationship between surface flux partitioning and precipitation.

\section{Discussion: Assessing the evaporation- precipitation feedback}

The results presented above highlight significant regional impacts of EF variability on afternoon rainfall probability over North America in both NARR and AM2.1, with a positive relationship between the EF and probability. Both NARR and AM2.1 further show the coupling strength as defined by TFS increasing as EF increases.
The dominance of a positive impact of evaporative fraction on subsequent precipitation is consistent with results from previous literature (e.g., Polcher 1995; De Ridder 1997; Xue et al. 2001) and understanding of the mechanistic pathways connecting the two variables. A simplified characterization of the impact of increased EF-resulting from increased evaporation-on precipitation is that enhanced evaporation reduces the convective inhibition through more efficient reduction (lowering) of the level of free convection (LFC) than the reduction (lowering) of the top of the boundary layer (BL) (Gentine et al. 2013c). High surface evaporation rates are typically associated with shallow boundary layers with high values of moist static energy (MSE), while high rates of sensible heat flux are typically associated with deep boundary layers with lower MSE (De Ridder 1997). The positive evaporation-precipitation pathway is characterized by a rise in BL MSE leading to an associated lowering of the LFC and reduced convective inhibition (CIN) until the LFC is close to the top of the mixed layer, leading to cumulus mass flux generation (Betts 1973; Arakawa and Schubert 1974; Gentine et al. 2013a,b).

Conversely, we hypothesize that the negative evaporation-precipitation pathway is characterized by increased relative humidity at the boundary layer top (Ek and Holtslag 2004; Westra et al. 2012) and therefore reduced LFC and CIN. This can happen in the case of weakly stratified and moist atmospheric profiles (Betts 1992; Gentine et al. 2013c) in which a deep boundary layer favors condensation by the reduction of the actual temperature at the boundary layer top. Stated another way, for a weakly stratified moist atmospheric profile, $\mathrm{BL}$ growth is a more efficient method for bringing together the BL top and LFC, while for a relatively drier and more stable profile, directly increasing surface MSE via moistening is a more efficient method of achieving this same result. 
Although the relaxed Arakawa-Schubert (RAS) convective scheme used in AM2.1 (Moorthi and Suarez 1992) does not explicitly simulate the impact of surface fluxes on convective layer properties as explained above, its parameterizations and behavior are consistent with a dominant positive impact of increased EF on rainfall triggering. In particular, for the RAS scheme, convection is triggered on a quantity similar to "entraining CAPE." Thus, increased latent heating at the surface feeds parcel buoyancy aloft through the effect of in situ condensational heating. While higher sensible heat flux may also directly increase buoyancy through warming at the surface, it also shifts saturation thresholds to higher values, which makes it more difficult for condensation to occur. Thus, in the RAS scheme, higher surface EF is more likely to lead to rainfall occurrence. On the other hand, the amount of rainfall that occurs depends on ambient conditions higher in the atmospheric column that are more strongly tied to large-scale dynamics.

As underscored in the introduction, the mechanistic pathway detailed above points to the impact of soil moisture anomalies and subsequent surface fluxes anomalies on boundary layer dynamics, convection, and precipitation formation, rather than to a change of the absolute water vapor input to the atmosphere from modified evapotranspiration (Seneviratne et al. 2010). The weak overall amplification feedback strength signal over North America in our results indicates that, at the temporal and spatial scales considered here, the variations in local moisture input to the atmosphere from evapotranspiration barely influence rainfall depths, which are mostly the result of synoptic advection of moisture. However, it should be noted that the morning EF modulation of afternoon rainfall triggering can impact the total rainfall depth viewed over sufficiently long periods (e.g., seasonally) by shifting the frequency of convective rainfall events.

To highlight this, we compute a combined feedback strength (CFS), which measures the impact of morning EF on afternoon rainfall amounts over the same days as included in the TFS computation-that is, once days with morning rain or negative morning CTP are removed (recalling here that AFS computes the same impact, in terms of rainfall amount variability, but on days with rainy afternoons only):

$$
\mathrm{CFS}=\sigma_{\mathrm{EF}} \frac{\overline{\partial E\left[r_{\text {alldays }}\right]}}{\partial \mathrm{EF}} .
$$

In effect, CFS measures the combined effects of the TFS (rainfall triggering) and the AFS (rainfall amplification); as shown by the results in section 3 , however, the TFS is by far the dominant signal. Figure 12a shows results for summer in the NARR dataset: when all days considered in the TFS are included, the variations in morning EF explain up to $0.5 \mathrm{~mm} \mathrm{day}^{-1}$ of the variations in afternoon rainfall amount. As expected, the CFS pattern reflects a combined TFS/AFS pattern: it is strongest over Mexico and the eastern United States. Compared to the average summer afternoon rainfall depth over the same days (i.e., on days included in the TFS/CFS analysis, Fig. 12b), it can be seen that over the regions of largest CFS more than $50 \%$ of afternoon rainfall amount variability on these days (up to $90 \%$ south of the Great Lakes) can be explained by variations in morning EF and subsequent impacts on rainfall triggering. Further scaling Fig. $12 \mathrm{~b}$ by the share of total seasonal rainfall occurring as afternoon rainfall on days included in the TFS/CFS analysis (Fig. 12c) then provides an estimate of how much of total seasonal rainfall variability can be considered as resulting from morning EF variability (Fig. 12d), for example, up to $40 \%$ over the Ohio River basin and up to around 50\% over northern Mexico and the U.S. Southwest. One may note that Fig. 12c further highlights the Midwestern minimum alluded to in section 2, that is, convective afternoon rainfall represents a smaller share of total rainfall there than anywhere else over the study domain because most rainfall there happens during nighttime (Ruane 2010). Overall, this analysis indicates that TFS values may translate to significant seasonal rainfall amount variability and, as a consequence, a large share of continental rainfall variability may be driven by EF variability through the control on rainfall frequency. One may note in Fig. 12d that this share is not necessarily strongest where the CFS itself is strongest, as these are also typically the regions of greatest rainfall depth, but rather it is strongest in regions where the CFS is still large but with comparatively lower afternoon rainfall amounts (e.g., northern Mexico and the Ohio River basin).

How do the present results compare to other assessments of the impacts of land surface fluxes on precipitation, for example, results from the GLACE experiment (Koster et al. 2004) or moisture recycling studies (e.g., Dominguez and Kumar 2008)? On first glance, there may appear to be some inconsistencies: for instance, Figs. 2 and 12c do not exhibit a central Great Plains hotspot as in the study of Koster et al. (2004). However, as discussed in Findell et al. (2011), this can be at least partly attributed to the difference in coupling metrics, as the Koster et al. metric not only considered the impact of evaporation on rainfall as analyzed here but also the impact of soil moisture on evaporation. In addition, the analysis of Koster et al. (2004) used total rainfall during the day, whereas our study focuses on afternoon rainfall only, thus not 


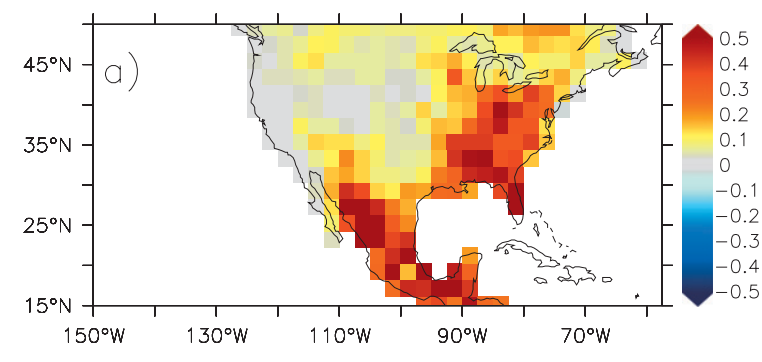

CFS, JJA $(\mathrm{mm} / \mathrm{d})$

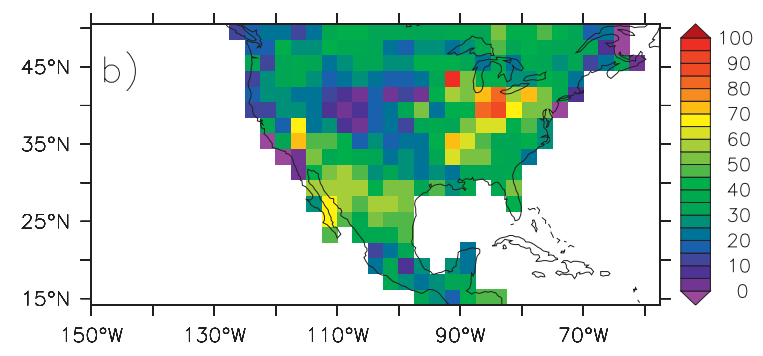

CFS/Mean.Aft.Rain on TFS.days*100

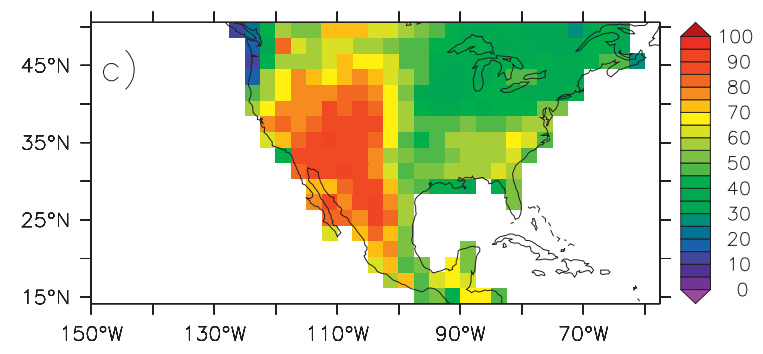

Total rain on TFS.days/total JJA rain $* 100$

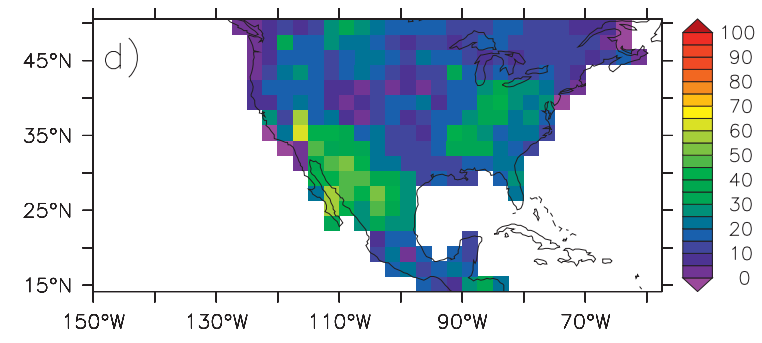

b) * c) $(\%)$

FIG. 12. (a) Combined feedback strength (CFS, (units of millimeters of afternoon rainfall) in NARR for JJA. (b) CFS divided by average afternoon rainfall on days included in the CFS (percent). (c) Ratio of total afternoon rainfall on days included in the CFS to total JJA rainfall (percent). (d) Product of (b) and (c) in percent.

accounting for rainfall during other times of day. Because the computation of the Koster et al. metric explicitly relies on model simulations in which soil moisture/evaporation variability are suppressed, we obviously cannot compute this metric from the NARR dataset for comparison. On the other hand, we note that, while AM2.1 essentially agrees with the distribution of strong EF-rainfall coupling evident in NARR, a similar model version also produced a strong positive signal over the central United States in the GLACE experiment, in agreement with the central Great Plains hotspot (cf. Fig. 5 in Koster et al. 2006). This suggests that both analyses are not inherently contradictory.

We can also reconcile our results in the context of moisture recycling studies (Brubaker et al. 1993; Dirmeyer and Brubaker 2007; Dirmeyer et al. 2009a,b). While the latter have typically yielded recycling ratios, that is, the share of precipitation over a given region originating from evaporation from the same region, on the order of $15 \%-35 \%$ over the contiguous United States (e.g., see Table 1 in Dominguez and Kumar 2008 and corresponding references), our analysis indicates that over North America the principal impact of evapotranspiration is on rainfall triggering, not rainfall amplification. Thus, while the fraction of afternoon rainfall variability explained by morning EF variability in our analysis (Fig. 12c) is comparable to, or even exceeds, the values provided by prior recycling studies, the underlying mechanistic pathway is distinct, that is, increased rainfall triggering versus rainfall enhancement. Of course, it is important to note that recycling ratios typically correspond to values integrated over longer periods (e.g., seasons or years) and over much larger regions than the daily time and pixel scales considered here. The conceptual difference between "local" evaporation-precipitation coupling, exemplified here by the TFS/AFS analysis, and implicitly larger-scale moisture budget studies has been noted in Seneviratne et al. (2010) and developed in greater detail in Goessling and Reick (2011). Fundamentally, recycling ratios can be regarded as an integral of local evaporation-precipitation coupling over time and space. Although local coupling may take place at smaller spatial and temporal scales, the absolute water input from evaporation to the atmosphere becomes significant only beyond a certain spatiotemporal scale (Goessling and Reick 2011; van der Ent and Savenije 2011); beyond this scale, the magnitude of moisture recycling generally increases as the area increases (Dominguez et al. 2006; van der Ent et al. 2010). The connection between such recycling ratio analyses and local surface-atmosphere coupling remains to be fully investigated; for instance, Goessling and Reick (2011) note that recycling ratios can only be positive, while local coupling is sometimes negative (Hohenegger et al. 2009). In any event, our analysis is on arguably too short a time scale to capture the moisture recycling highlighted in studies such as Dominguez and Kumar 
(2008). We hypothesize that at both a longer time scale and a larger spatial scale, the balance between the TFS and AFS in our analysis should shift toward stronger AFS values, that is, the effect of evaporation aggregated over pixels and/or days should impact corresponding rainfall depths more clearly. In this regard, it is interesting to note that the dominant role of triggering feedback strength compared to amplification feedback strength still holds in NARR when averaging data from the original fine spatial resolution, as shown in Findell et al. (2011), to the coarser, model-like resolution in the present study: even at this larger scale $\left(2.5^{\circ} \times 2.0^{\circ}\right)$ there is little apparent moisture recycling on a diurnal basis.

Finally, the relationship between surface fluxes and precipitation as assessed in the present study, within the same pixel independently of neighboring ones, needs to be articulated with other studies emphasizing mesoscale land-atmosphere interactions. Such studies indicate that, on scales of 10-100 km, sharp gradients in surface fluxes induced by soil moisture or vegetation patterns may generate daytime mesoscale circulations (analogous to sea breezes), resulting in enhanced convergence and convection over warm surface anomalies. For instance, studies based on remote sensing data have shown that in regions as varied as West Africa (Taylor et al. 2011), the Amazon (Wang et al. 2009), or the Midwest (Carleton et al. 2008), convection may be favored over drier areas in the presence of such surface heterogeneity. Most recently, using recent global high-resolution $\left(0.25^{\circ}\right)$ satellite retrievals of soil moisture and precipitation, Taylor et al. (2012) have shown a globally consistent negative feedback in which afternoon precipitation occurs preferentially over soils that are relatively dry compared to the surrounding area, with the strongest signal emerging in semiarid regions. Although their analysis does not clearly show a strong signal over North America, their results and those of Findell et al. (2011), which are obtained at similar time and spatial scales, appear conceptually contradictory. Part of the difference in results may stem from the differences between the metrics themselves: the TFS framework of Findell et al. (2011) does not account for heterogeneity between pixels, contrary to Taylor et al. (2012). In addition, Taylor et al.'s (2012) analysis is based on topsurface soil moisture (SM) as measured by microwave remote sensing (i.e., a few centimeters deep at most), not EF: the two may not always be well correlated (Seneviratne et al. 2010). The sensitivity of rainfall to SM among neighboring pixels in Taylor et al. (2012) can be seen as a conditional sensitivity (e.g., the expected value of the conditional sensitivity to $\mathrm{SM}$ ), conditioned on neighboring values:

$$
E\left(\frac{\partial \Gamma(r)}{\partial \mathrm{SM}} \mid \text { neighboring SM }\right) .
$$

Its relationship to the TFS computed here, which corresponds to a partial derivative unconditioned to neighboring pixels and using $\mathrm{EF}[E(\partial \Gamma(r) / \partial \mathrm{EF})]$, is determined by the respective spatial structures of EF and SM, which depends on the spatial statistics of rainfall in the first place and surface thereafter (soil and vegetation conditions). Mesoscale effects could potentially be investigated in the NARR dataset; however, how they may be incorporated in the Findell et al.'s (2011) analytic framework is not immediately obvious. On the other hand, we do note, along with Koster (2011), that a local dry-soil advantage may be viewed as a way of redistributing rainfall locally and does not preclude an overall positive feedback between EF and precipitation at spatial scales larger than the typical length scale of such mesoscale interactions. In that regard, at the coarse model-like resolution used here, our assessment of the EF-precipitation relationship may not necessarily be incompatible with assessments of mesoscale land-atmosphere interactions.

\section{Summary and conclusions}

In this study we have expanded the NARR-based assessment of the impact of morning surface fluxes on afternoon precipitation frequency and intensity of Findell et al. (2011) to include all seasons and to compare with a simulation of the GFDL AM2.1 general circulation model. Our results demonstrate general agreement between NARR and AM2.1 for the main features described in Findell et al. (2011), most significantly that higher early-morning evaporative fraction (EF) strongly modulates afternoon convective rainfall triggering but does not strongly influence rainfall amounts. Spatially, both NARR and AM2.1 TFS exhibit largest values over the eastern United States and Mexico. Moreover, the seasonality of the evaporation-rainfall coupling is consistent between NARR and AM2.1, with the strength peaking in summer in both. Functionally, the coupling strength increases in both datasets with increasing mean $\mathrm{EF}$, with the steepest increase above $\sim 0.6$. Over the regions with the strongest signal, we estimate that the impact of EF variability on summertime afternoon rainfall triggering may account for up to half of the aggregate seasonal rainfall amount variability. Since our analysis is restricted to the morning-to-afternoon impact of surface fluxes on precipitation, our analysis may not provide an accurate estimate of how much daytime surface fluxes might impact subsequent convective precipitation in regions like the Midwest where convection exhibits a nocturnal phasing. 
While there is an overall correspondence of TFS in NARR and AM2.1, some notable differences are evident. We speculate that climatological biases in rainfall contribute to differences between NARR and AM2.1, with the latter displaying some regional triggering feedback strength signals that are not present in NARR (e.g., the northern Great Plains and Rockies). It is also worth noting that NARR and AM2.1 yield comparable TFS signals through different combinations of factors: in general, AM2.1 simulates lower sensitivity of afternoon rainfall probability to morning EF but larger variability in EF. These results underscore the need to consider evaporative fraction and its coupling to precipitation in additional datasets and model simulations in order to assess the applicability of our results across models and to validate against available measurements, even though the limited availability of current measurements may preclude obtaining robust observational estimates. Systematic comparison to other land-atmosphere coupling metrics based on common datasets would also be useful in order to develop an interpretative framework for the existing studies of land-atmosphere coupling and their respective results. In this regard, we stress that our analysis focuses on the atmospheric branch of the coupling (i.e., the impact of surface fluxes on rainfall) at diurnal time and order 102-km spatial scales. In future work, we plan to expand calculation of the metric to make it applicable to the complete soil moisture-precipitation pathway.

Acknowledgments. This work was supported by National Science Foundation (NSF) Grants AGS-1035968 and AGS-1035843 and New Jersey Agricultural Experiment Station Hatch Grant NJ07102. We thank Sarah Kapnick and Leo Donner for providing comments on the manuscript and Fanrong Zeng for assisting with the simulation. National Centers for Environmental Prediction (NCEP) North American Regional Reanalysis (NARR) data provided by the National Climatic Data Center from their website: http://nomads.ncdc.noaa.gov/ data.php.

\section{REFERENCES}

Alfieri, L., P. Claps, P. D’Odorico, F. Laio, and T. M. Over, 2008: An analysis of the soil moisture feedback on convective and stratiformprecipitation. J. Hydrometeor., 9, 280-291.

Arakawa, A., and W. Schubert, 1974: Interaction of a cumulus cloud ensemble with the large-scale environment, Part I. J. Atmos. Sci., 31, 674-701.

Becker, E. J., E. H. Berbery, and R. W. Higgins, 2009: Understanding the characteristics of daily precipitation over the United States using the North American Regional Reanalysis. J. Climate, 22, 6268-6286.

Betts, A. K., 1973: Non-precipitating cumulus convection and its parameterization. Quart. J. Roy. Meteor. Soc., 99, 178-196.
_ 1992: FIFE atmospheric boundary layer budget methods. J. Geophys. Res., 97, 18 523-18 531.

_ cipitation, surface thermodynamics, and surface fluxes in the ECMWF model using LBA data. J. Geophys. Res., 107, 8045, doi:10.1029/2001JD000427.

Bouttier, F., J. Mahfouf, and J. Noilhan, 1993: Sequential assimilation of soil-moisture from atmospheric low-level parameters. Part I: Sensitivity and calibration studies. J. Appl. Meteor., 32, 1335-1351.

Brubaker, K., D. Entekhabi, and P. Eagleson, 1993: Estimation of Continental precipitation recycling. J. Climate, 6, 1077-1089.

Bukovsky, M., and D. Karoly, 2007: A brief evaluation of precipitation from the North American Regional Reanalysis. J. Hydrometeor., 8, 837-846.

Carleton, A. M., D. J. Travis, J. O. Adegoke, D. L. Arnold, and S. Curran, 2008: Synoptic circulation and land surface influences on convection in the Midwest U.S. "Corn Belt" during the summers of 1999 and 2000. Part II: Role of vegetation boundaries. J. Climate, 21, 3617-3641.

Conil, S., H. Douville, and S. Tyteca, 2009: Contribution of realistic soil moisture initial conditions to boreal summer predictability. Climate Dyn., 32, 75-93.

Cook, B. I., G. B. Bonan, and S. Levis, 2006: Soil moisture feedbacks to precipitation in South Africa. J. Climate, 19, 4198-4206.

Dai, A., 2006: Precipitation characteristics in eighteen coupled climate models. J. Climate, 19, 4605-4630.

, F. Giorgi, and K. E. Trenberth, 1999: Observed and modelsimulated diurnal cycles of precipitation over the contiguous United States. J. Geophys. Res., 104, 6377-6402.

Davin, E. L., N. de Noblet-Ducoudré, and P. Friedlingstein, 2007: Impact of land cover change on surface climate: Relevance of the radiative forcing concept. Geophys. Res. Lett., 34, L13702, doi:10.1029/2007GL029678.

Delworth, T. L., and Coauthors, 2006: GFDL's CM2 global coupled climate models. Part I: Formulation and simulation characteristics. J. Climate, 19, 643-674.

De Ridder, K., 1997: Land surface processes and the potential for convective precipitation. J. Geophys. Res., 102, 30 085-30 090.

Dirmeyer, P. A., 2003: The role of the land surface background state in climate predictability. J. Hydrometeor., 4, 599-610.

- 2005: The land surface contribution to the potential predictability of boreal summer season climate. J. Hydrometeor., 6, 618-632.

- and K. L. Brubaker, 2007: Characterization of the global hydrologic cycle from a back-trajectory analysis of atmospheric water vapor. J. Hydrometeor., 8, 20-37.

,-- , and T. DelSole, 2009a: Import and export of atmospheric water vapor between nations. J. Hydrol., 365, 11-22, doi:10.1016/j.jhydrol.2008.11.016.

— C. A. Schlosser, and K. L. Brubaker, 2009b: Precipitation, recycling, and land memory: An integrated analysis. J. Hydrometeor., 10, 278-288.

Dominguez, F., and P. Kumar, 2008: Precipitation recycling variability and ecoclimatological stability-A study using NARR data. Part I: Central U.S. Plains ecoregion. J. Climate, 21, $5165-5186$.

,$- \ldots$, X. Liang, and M. Ting, 2006: Impact of atmospheric moisture storage on precipitation recycling. J. Climate, 19, 1513-1530.

Douville, H., 2004: Relevance of soil moisture for seasonal atmospheric predictions: Is it an initial value problem? Climate Dyn., 22, 429-446. 
Ek, M., and A. Holtslag, 2004: Influence of soil moisture on boundary layer cloud development. J. Hydrometeor., 5, 86-99.

Eltahir, E. A. B., and R. L. Bras, 1996: Precipitation recycling. Rev. Geophys., 34, 367-378.

Entekhabi, D., and K. Brubaker, 1995: An analytic approach to modeling land atmosphere interaction: 2. Stochastic formulation. Water Resour. Res., 31, 633-643.

Findell, K. L., and E. A. B. Eltahir, 2003a: Atmospheric controls on soil moisture-boundary layer interactions. Part I: Framework development. J. Hydrometeor., 4, 552-569.

, and _ 2003b: Atmospheric controls on soil moistureboundary layer interactions. Part II: Feedbacks within the continental United States. J. Hydrometeor., 4, 570-583.

— E. Shevliakova, P. C. D. Milly, and R. J. Stouffer, 2007: Modeled impact of anthropogenic land cover change on climate. J. Climate, 20, 3621-3634.

—, P. Gentine, B. R. Lintner, and C. Kerr, 2011: Probability of afternoon precipitation in eastern United States and Mexico enhanced by high evaporation. Nat. Geosci., 4, 434-439.

Fischer, E. M., S. I. Seneviratne, D. Lüthi, and C. Schär, 2007: The contribution of land-atmosphere coupling to recent European summer heatwaves. Geophys. Res. Lett., 34, L06707, doi:10.1029/ 2006GL029068.

Gentine, P., D. Entekhabi, A. Chehbouni, G. Boulet, and B. Duchemin, 2007: Analysis of evaporative fraction diurnal behaviour. Agric. For. Meteor., 143, 13-29, doi:10.1016/ j.agrformet.2006.11.002.

,$- \ldots$, and J. Polcher, 2010: Spectral behaviour of a coupled land-surface and boundary-layer system. Bound.-Layer Meteor., 134, 157-180, doi:10.1007/s10546-009-9433-z.

$\longrightarrow, \ldots$, and $\_, 2011 \mathrm{a}$ : The diurnal behavior of evaporative fraction in the soil-vegetation-atmospheric boundary layer continuum. J. Hydrometeor., 12, 1530-1546.

- J. Polcher, and D. Entekhabi, 2011b: Harmonic propagation of variability in surface energy balance within a coupled soil-vegetation-atmosphere system, Water Resour. Res., 47, W05525, doi:10.1029/2010WR009268.

_ A. Betts, K. Findell, B. Lintner, A. Tzella, and F. D'Andrea, 2013a: A probabilistic-bulk model of coupled mixed layer and convection. Part I: Clear-sky case. J. Atmos. Sci., in press.

,,,$--- \ldots$, and F. D'Andrea, 2013b: A probabilisticbulk model of coupled mixed layer and convection. Part II: Shallow convection case. J. Atmos. Sci., in press.

— A. A. M. Holtslag, F. D'Andrea, and M. Ek, 2013c: Surface and atmospheric controls on moist convection onset over land. J. Hydrometeor., in press.

GFDL Global Atmospheric Model Development Team, 2004: The new GFDL global atmosphere and land model AM2-LM2: Evaluation with prescribed SST simulations. J. Climate, 17, 4641-4673.

Goessling, H. F., and C. H. Reick, 2011: What do moisture recycling estimates tell us? Exploring the extreme case of nonevaporating continents. Hydrol. Earth Syst. Sci., 15, 32173235, doi:10.5194/hess-15-3217-2011.

Guo, Z. C., and Coauthors, 2006: GLACE: The Global LandAtmosphere Coupling Experiment. Part II: Analysis. J. Hydrometeor., 7, 611-625.

Hohenegger, C., P. Brockhaus, C. S. Bretherton, and C. Schär, 2009: The soil moisture-precipitation feedback in simulations with explicit and parameterized convection. J. Climate, 22, 5003-5020.

Hurrell, J., J. Hack, D. Shea, J. Caron, and J. Rosinski, 2008: A new sea surface temperature and sea ice boundary data set for the Community Atmosphere Model. J. Climate, 21, 5145-5153.
Klein, S. A., X. Jiang, J. S. Boyle, S. Malyshev, and S. Xie, 2006: Diagnosis of the summertime warm and dry bias over the U.S. Southern Great Plains in the GFDL climate model using a weather forecasting approach. Geophys. Res. Lett., 33, L18805, doi:10.1029/2006GL027567.

Koster, R. D., 2011: Climate science: Storm instigation from below. Nat. Geosci., 4, 427-428.

_ , and M. Suarez, 2003: Impact of land surface initialization on seasonal precipitation and temperature prediction. J. Hydrometeor., 4, 408-423.

— , and Coauthors, 2004: Regions of strong coupling between soil moisture and precipitation. Science, 305, 1138-1140.

- , and Coauthors, 2006: GLACE: The Global Land-Atmosphere Coupling Experiment. Part I: Overview. J. Hydrometeor., 7, 590-610.

_ - and Coauthors, 2011: The second phase of the Global LandAtmosphere Coupling Experiment: Soil moisture contributions to subseasonal forecast skill. J. Hydrometeor., 12, 805-822.

Lawrence, D. M., and J. M. Slingo, 2005: Weak land-atmosphere coupling strength in HadAM3: The role of soil moisture variability. J. Hydrometeor., 6, 670-680.

Lee, J.-E., B. R. Lintner, C. K. Boyce, and P. J. Lawrence, 2011: Land use change exacerbates tropical South American drought by sea surface temperature variability. Geophys. Res. Lett., $\mathbf{3 8}$, L19706, doi:10.1029/2011GL049066.

Liang, X.-Z., L. Li, A. Dai, and K. E. Kunkel, 2004: Regional climate model simulation of summer precipitation diurnal cycle over the United States. Geophys. Res. Lett., 31, L24208, doi:10.1029/2004GL021054.

Lin, S.-J., 2004: A "vertically Lagrangian" finite-volume dynamical core for global models. Mon. Wea. Rev., 132, 2293-2307.

Mahfouf, J. F., 1991: Analysis of soil moisture from near-surface parameters: A feasibility study. J. Appl. Meteor., 30, 1534-1547.

Mesinger, F., and Coauthors, 2006: North American Regional Reanalysis. Bull. Amer. Meteor. Soc., 87, 343-360.

Milly, P. C. D., and A. B. Shmakin, 2002: Global modeling of land water and energy balances. Part I: The Land Dynamics (LaD) model. J. Hydrometeor., 3, 283-299.

Moorthi, S., and M. J. Suarez, 1992: Relaxed Arakawa-Schubert: A parameterization of moist convection for general circulation models. Mon. Wea. Rev., 120, 978-1002.

Orlowsky, B., and S. I. Seneviratne, 2010: Statistical analyses of land-atmosphere feedbacks and their possible pitfalls. J. Climate, 23, 3918-3932.

Paegle, J., K. C. Mo, and J. Nogues-Paegle, 1996: Dependence of simulated precipitation on surface evaporation during the 1993 United States summer floods. Mon. Wea. Rev., 124, 345-361.

Pal, J. S., and E. A. B. Eltahir, 2003: A feedback mechanism between soil moisture distribution and storm tracks. Quart. J. Roy. Meteor. Soc., 129, 2279-2297.

Pielke, R. A., Sr., 2001: Influence of the spatial distribution of vegetation and soils on the prediction of cumulus convective rainfall. Rev. Geophys., 39, 151-177.

Pitman, A. J., and Coauthors, 2009: Uncertainties in climate responses to past land cover change: First results from the LUCID intercomparison study. Geophys. Res. Lett., 36, L14814, doi:10.1029/2009GL039076.

Polcher, J., 1995: Sensitivity of tropical convection to land surface processes. J. Atmos. Sci., 52, 3143-3161.

Pongratz, J., C. Reick, T. Raddatz, and M. Claussen, 2010: Biogeophysical versus biogeochemical climate response to historical anthropogenic land cover change. Geophys. Res. Lett., 37, L08702, doi:10.1029/2010GL043010. 
Rio, C., F. Hourdin, J.-Y. Grandpeix, and J.-P. Lafore, 2009: Shifting the diurnal cycle of parameterized deep convection over land. Geophys. Res. Lett., 36, L07809, doi:10.1029/2008GL036779.

Rodriguez-Iturbe, I., D. Entekhabi, and R. L. Bras, 1991a: Nonlinear dynamics of soil moisture at climate scales: 1 . Stochastic analysis. Water Resour. Res., 27, 1899-1906.

$\longrightarrow, \ldots$, J. Lee, and R. L. Bras, 1991b: Nonlinear dynamics of soil moisture at climate scales: 2. Chaotic analysis. Water Resour. Res., 27, 1907-1915.

Ruane, A. C., 2010: NARR's atmospheric water cycle components. Part II: Summertime mean and diurnal interactions. J. Hydrometeor., 11, 1220-1233.

Seneviratne, S. I., and R. D. Koster, 2012: A revised framework for analyzing soil moisture memory in climate data: Derivation and interpretation. J. Hydrometeor., 13, 404-412.

—, T. Corti, E. L. Davin, M. Hirschi, E. B. Jaeger, I. Lehner, B. Orlowsky, and A. J. Teuling, 2010: Investigating soil moisture climate interactions in a changing climate: A review. Earth Sci. Rev., 99, 125-161.

Sutton, C., T. M. Hamill, and T. T. Warner, 2006: Will perturbing soil moisture improve warm-season ensemble forecasts? A proof of concept. Mon. Wea. Rev., 134, 3174-3189.

Taylor, C. M., A. Gounou, F. Guichard, P. P. Harris, R. J. Ellis, F. Couvreux, and M. de Kauwe, 2011: Frequency of Sahelian storm initiation enhanced over mesoscale soil-moisture patterns. Nat. Geosci., 4, 430-433.

— R. A. M. De Jeu, F. Guichard, P. P. Harris, and W. A. Dorigo, 2012: Afternoon rain more likely over drier soils. Nature, 489, 423-426.

Teuling, A. J., and Coauthors, 2010: Contrasting response of European forest and grassland energy exchange to heatwaves. Nat. Geosci., 3, 722-727, doi:10.1038/ngeo950.

van der Ent, R. J., and H. H. G. Savenije, 2011: Length and time scales of atmospheric moisture recycling. Atmos. Chem. Phys., 11, 1853-1863, doi:10.5194/acp-11-1853-2011.
,,-- B. Schaefli, and S. C. Steele-Dunne, 2010: Origin and fate of atmospheric moisture over continents. Water Resour. Res., 46, W09525, doi:10.1029/2010WR009127.

Vautard, R., and Coauthors, 2007: Summertime European heat and drought waves induced by wintertime Mediterranean rainfall deficit. Geophys. Res. Lett., 34, L07711, doi:10.1029/ 2006 GL028001.

Wang, J. F., and Coauthors, 2009: Impact of deforestation in the Amazon basin on cloud climatology. Proc. Natl. Acad. Sci. USA, 106, 3670-3674.

Wei, J., R. E. Dickinson, and H. Chen, 2008: A negative soil moisture-precipitation relationship and its causes. J. Hydrometeor., 9, 1364-1376.

Weisheimer, A., F. J. Doblas-Reyes, T. Jung, and T. N. Palmer, 2011: On the predictability of the extreme summer 2003 over Europe. Geophys. Res. Lett., 38, L05704, doi:10.1029/2010GL046455.

Westra, D., G. J. Steeneveld, and A. A. M. Holtslag, 2012: Some observational evidence for dry soils supporting enhanced relative humidity at the convective boundary layer top. J. Hydrometeor., 13, 1347-1358.

Xue, Y., F. Zeng, K. Mitchell, Z. Janjic, and E. Rogers, 2001: The impact of land surface processes on simulations of the U.S. hydrological cycle: A case study of the 1993 flood using the SSiB land surface model in the NCEP Eta regional model. Mon. Wea. Rev., 129, 2833-2860.

Zeng, N., and J. D. Neelin, 1999: A land-atmosphere interaction theory for the tropical deforestation problem. J. Climate, 12, $857-872$.

Zeng, X., M. Barlage, C. Castro, and K. Fling, 2010: Comparison of land-precipitation coupling strength using observations and models. J. Hydrometeor., 11, 979-994.

Zhang, J., W.-C. Wang, and J. Wei, 2008: Assessing land-atmosphere coupling using soil moisture from the Global Land Data Assimilation System and observational precipitation. J. Geophys. Res., 113, D17119, doi:10.1029/2008JD009807. 